\title{
On the Low-Temperature Response of Semiconductor Gas Sensors
}

\author{
A. Helwig, ${ }^{1}$ G. Müller, ${ }^{1}$ G. Sberveglieri, ${ }^{2}$ and M. Eickhoff ${ }^{3}$ \\ ${ }^{1}$ EADS Innovation Works, Sensors, Electronics \& Systems Integration, 81663 München, Germany \\ ${ }^{2}$ CNR-INFM, SENSOR Laboratory, University of Brescia, 25133 Brescia, Italy \\ ${ }^{3}$ I. Physikalisches Institut, Justus Liebig Universität Gießen, 35392 Gießen, Germany \\ Correspondence should be addressed to A. Helwig, andreas.helwig@eads.net
}

Received 29 January 2009; Accepted 29 March 2009

Recommended by Yongxiang Li

\begin{abstract}
The present paper compares three different kinds of semiconductor gas sensing materials: metal oxides (MOX), hydrogenterminated diamond (HD), and hydrogenated amorphous silicon (a-Si:H). Whereas in MOX materials oxygen is the chemically reactive surface species, $\mathrm{HD}$ and a-Si:H are covalently bonded semiconductors with hydrogenterminated surfaces. We demonstrate that these dissimilar semiconductor materials exhibit the same kind of low-temperature gas response. This low-temperature response-mechanism is mediated by a thin layer of adsorbed water with the semiconductor materials themselves acting as $\mathrm{pH}$ sensors. In this adsorbate-limited state the gas sensitivity is limited to molecular species that can easily dissolve in $\mathrm{H}_{2} \mathrm{O}$ and subsequently undergo electrolytic dissociation. At higher temperatures, where a closed layer of adsorbed water can no longer exist, the gas response is limited by direct molecule-semiconductor interactions. In this latter mode of operation, MOX gas sensors respond to adsorbed gases according to their different oxidising or reducing properties. Hydrogenated amorphous silicon (a-Si:H), on the other hand, exhibits a significantly different cross sensitivity profile, revealing that gas-surface interactions may largely be restricted to analyte molecules with lone-pair and electron-deficient three-centre orbitals.
\end{abstract}

Copyright () 2009 A. Helwig et al. This is an open access article distributed under the Creative Commons Attribution License, which permits unrestricted use, distribution, and reproduction in any medium, provided the original work is properly cited.

\section{Introduction}

In recent years semiconductor gas sensors have found widespread commercial application in gas monitoring and alarm applications. To date most of these sensors employ metal oxide (MOX) semiconductors as gas sensitive materials [1-7]. Commercial MOX sensors mostly employ thick-film materials as sensing layers due to the fact that thick-film technologies are intrinsically low cost and that thick-film compositions can easily be controlled, allowing for the preparation of a wide range of MOX base materials and incorporation of numerous catalytic promoter impurities $[3,8]$. In this way MOX gas sensors with different cross sensitivity profiles can be realised. Most recent advances in this field are three-sensor arrays deposited on a single ceramic heater chip. These three-sensor arrays are embedded in a single TO5 package and are marketed together with data acquisition boards and principal component analysis software [9].

In spite of this progress, MOX gas sensors have remained a subject of intense scientific interest, mainly because of two challenges: (i) the limited selectivity of MOX gas sensors and (ii) their relatively large heating power consumption which makes MOX sensors and in particular MOX sensor arrays hard to employ in mobile applications and in busconnected sensor networks. Whereas micromachined heater technologies have been investigated to decrease the heating power consumption of MOX gas sensor arrays [10-14], recent efforts have been focused on the preparation of MOX nanocrystals or nanowires [15-19]. Due to their very constrained geometry and good thermal insulation, selfheating effects in single nanowire sensors can be quite appreciable, thus opening up new ways towards ultralow power-heated MOX gas sensors [20]. Concerning progress in the fields of sensitivity, selectivity, and stability, nanowire technologies have considerably enhanced the sensitivity and the stability of MOX gas sensors but contributed relatively little towards a solution of the cross sensitivity problem.

A third line of research, which has attracted attention in the past few years, is the low-temperature sensitivity of MOX gas sensors. Work into this direction has shown that MOX gas sensors cannot only respond to gases at conventional operation temperatures of the order of several hundred centigrade but also at room temperature and slightly above 
[21-26]. In this latter mode of operation UV photoactivation has also been shown to be effective [27-31]. Gases that could be detected under such conditions are $\mathrm{NO}_{2}, \mathrm{NH}_{3}, \mathrm{H}_{2} \mathrm{~S}$, and a number of short-chain alcohols.

Although interesting from a phenomenological point of view, all these latter reports remain vague in providing a consistent explanation for these novel low-temperature sensing phenomena. The present paper intends to contribute to this discussion, summarising results from recent work on the low-temperature response of semiconductor gas sensors [32-35]. Comprehensive presentation of these data in a single review aims at developing a coherent picture of low-temperature gas sensing phenomena at semiconductor surfaces. As will be shown below, the essence of our findings is that semiconductor materials in general-and MOX materials in particular — tend to adsorb multiple layers of humidity from the ambient air, forming a closed liquid electrolyte layer on the surface. In this water adsorptionlimited state, saturated semiconductor surfaces do not respond to changes in the ambient $\mathrm{H}_{2} \mathrm{O}$ vapour pressure, and their response to reactive gases is limited to molecules that can easily dissolve in water and undergo electrolytic dissociation there. The active sensing layer in this case is the adsorbed water film, and the role of the underlying semiconductor materials is simply reduced towards serving as a $\mathrm{pH}$ sensor. In our previous work we have coined the term "dissociative gas sensing effect" for this kind of gas sensing mechanism.

In the following we develop this idea of a dissociative gas sensing effect by reviewing some relevant observations on MOX materials. We then provide the reader with the theoretical background for the analysis of low-temperature multilayer water adsorption phenomena. In the central part of this article we discuss gas sensing experiments that have been performed on hydrogen-terminated diamond (HD) surfaces. The reason for considering such a dissimilar semiconductor material is - that in contrast to the huge variety of MOX materials with their widely variable composition and morphology-HD is a well-characterised single-crystal material with a well-documented adsorbed liquid electrolyte layer on top [36, 37]. HD, therefore, has turned out to be an ideal model system for studying the dissociative gas sensing effect $[33,34]$. As a third kind of semiconductor material, we have studied hydrogenated amorphous silicon (a-Si:H). The interest in this latter material stems from the fact that it can easily be incorporated into microsensor processes, exhibiting at the same time both a room-temperature dissociative gas sensing effect and an innovative kind of "coordinative gas response" that appears when the sensor operation temperature is raised above the water evaporation threshold [35]. In the final chapter we present a comprehensive model for the dissociative gas response, considering the partial steps of gas/liquid electrolyte and liquid electrolyte/semiconductor interactions.

\section{Observations on Metal Oxide Gas Sensors}

2.1. High-Temperature Response. As summarised in Figure 1, MOX gas sensors exhibit broad-range sensitivity to a wide
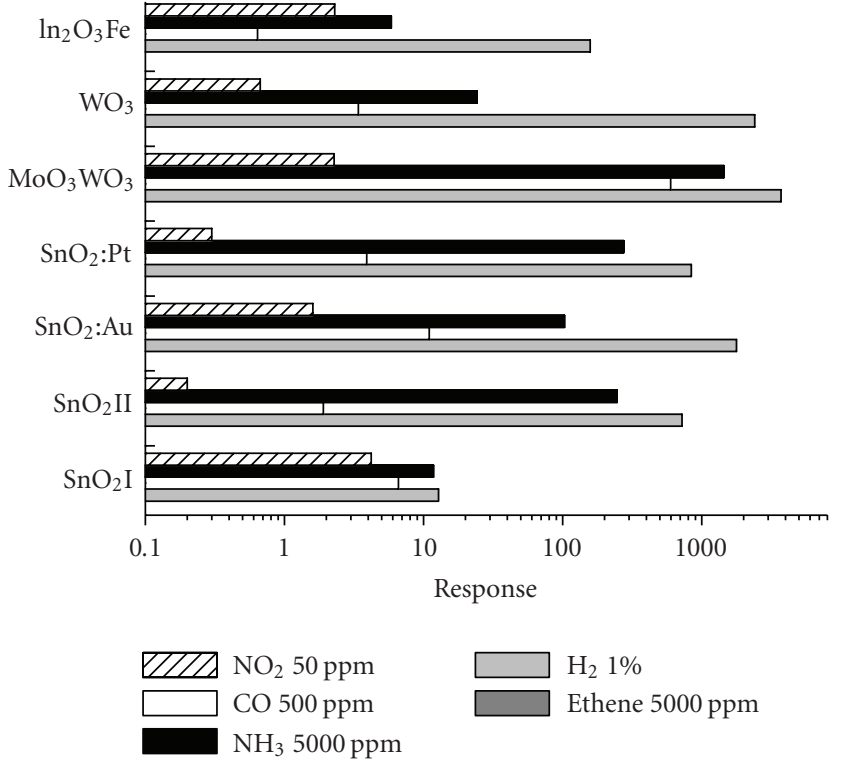

FIGURE 1: Gas sensitivity profiles of different MOX materials.

variety of analyte molecules. This broad-range sensitivity is due to the well-known combustive gas sensing effect in which adsorbed analyte molecules become oxidised by interactions with preadsorbed surface oxygen ions $[2-4,8]$. In all cases a major sensitivity also occurs in the case of $\mathrm{NO}_{2}$ which competes with $\mathrm{O}_{2}$ in forming negative surface ion species.

A key observation on MOX gas sensors is that those chemical surface interactions that lead to a combustive gas response are thermally activated. This fact is evidenced in Figure 2, which shows the $\mathrm{H}_{2}$ and the water vapour sensitivities of an $\mathrm{SnO}_{2}$ : $\mathrm{Au}$ sensor [39] as a function of its operation temperature. As far as reducing analyte molecules are concerned, the shape of these sensitivity curves can be understood on the basis of two opposite trends: (i) a thermally activated surface combustion of the adsorbed analyte molecules which limits the response on the low-temperature side and (ii) a thermally activated and concentration-dependent desorption rate which limits the response at the high-temperature side $[8,38]$. Figure 3 shows how the combination of both effects determines the temperature dependence of the gas response.

2.2. Low-Temperature Response. A significant new observation was that, in addition to this high-temperature gas sensitivity, MOX gas sensors also exhibit a small and slow and thus easily overlooked low-temperature response. There have been a number of reports, demonstrating sensitivity towards $\mathrm{NO}_{2}, \mathrm{NH}_{3}, \mathrm{H}_{2} \mathrm{~S}$, and different alcohol vapours even at room temperature $[21,22,31]$. Some of these reports also demonstrate an enhancement of this low-temperature gas response upon irradiation with UV light [27-30]. A consistent explanation of the underlying sensing mechanism, however, is not given in these reports. More recently we have demonstrated that this low-temperature response exhibits a different cross sensitivity profile in comparison to the conventional combustive high-temperature response. This 


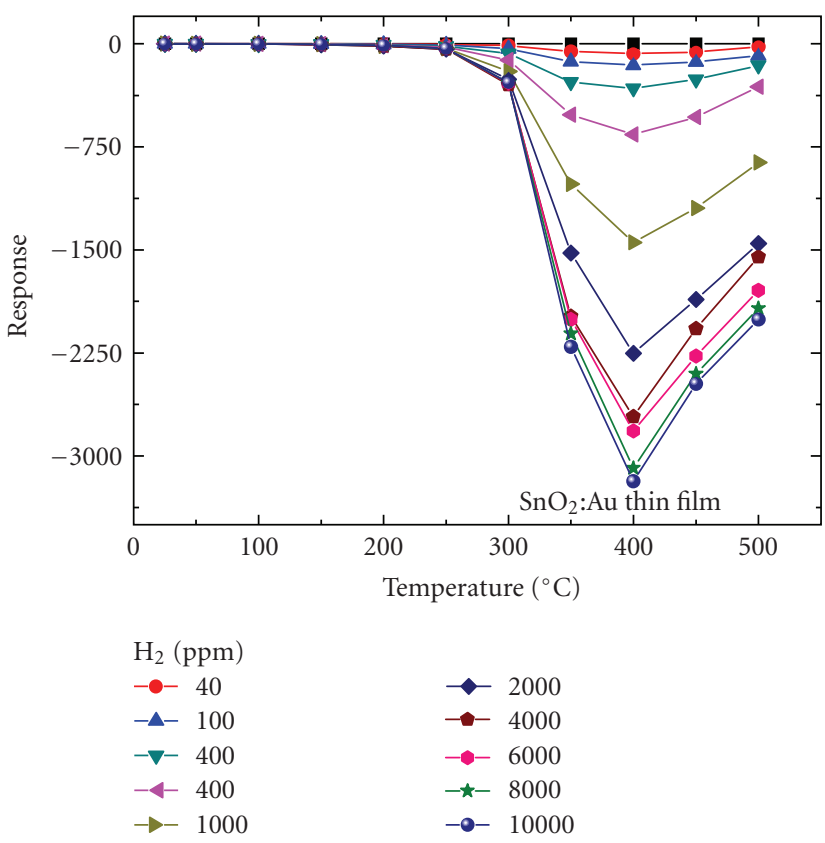

(a)
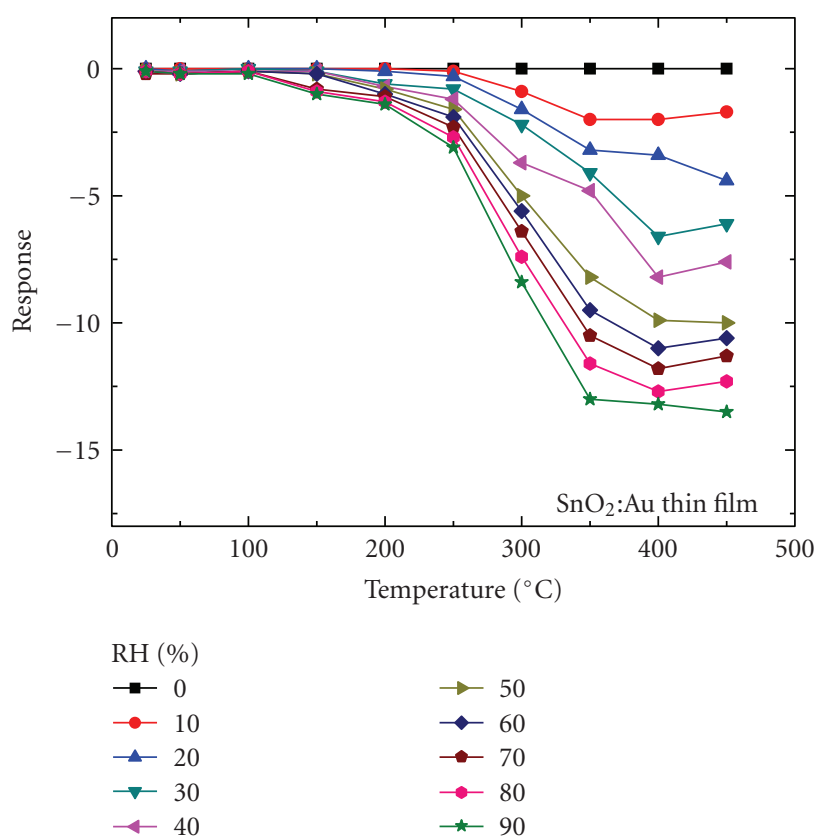

(b)

FIGURE 2: Surface temperature dependence of the sensitivity of a $\mathrm{SnO}_{2}$ :Au gas sensor: (a) towards $\mathrm{H}_{2}$; (b) towards water vapour.

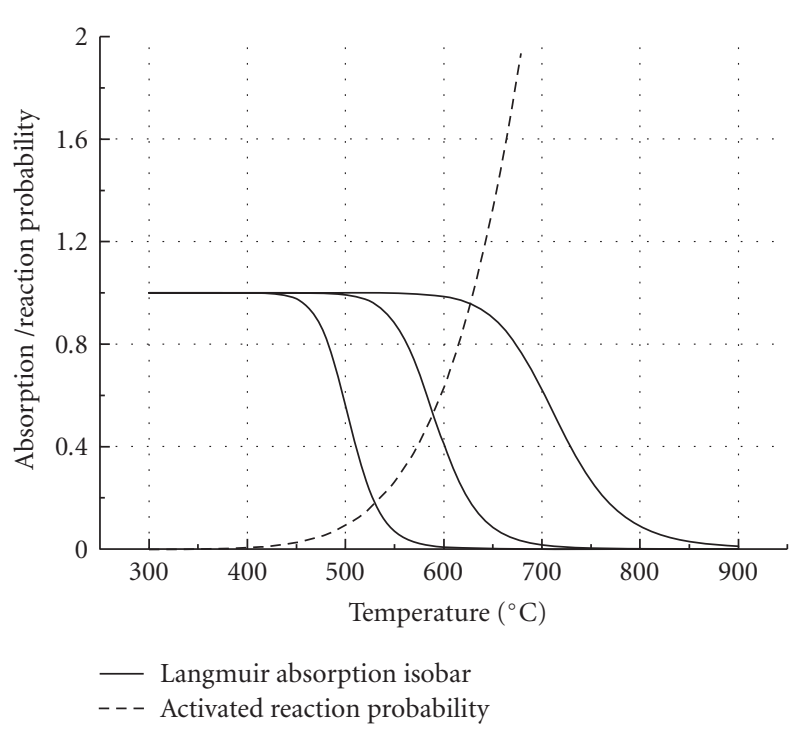

(a)

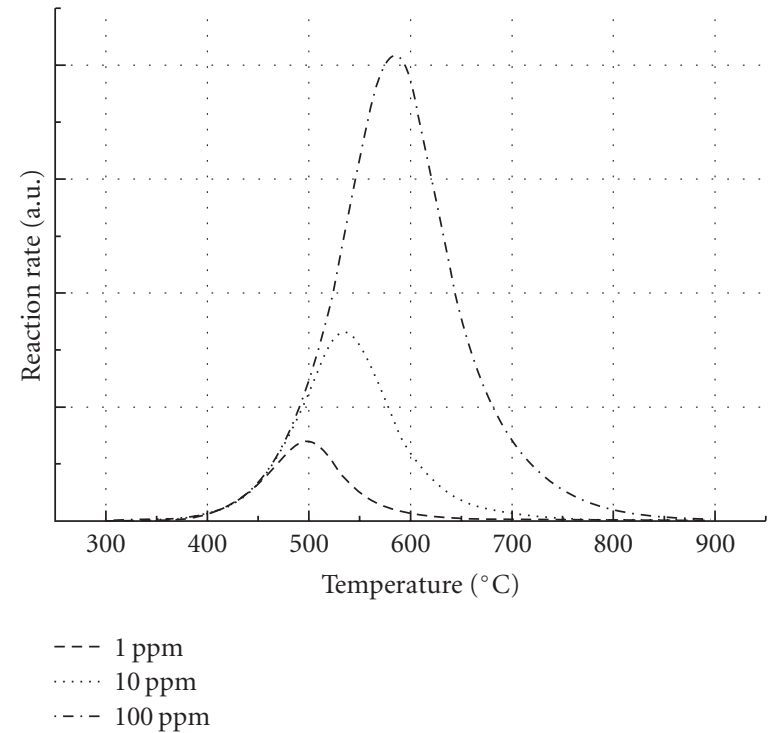

(b)

Figure 3: (a) Temperature dependence of the surface combustion and desorption rates of reducing analyte molecules; (b) cooperation of both effects in determining the temperature dependence of the MOX gas sensitivity [38].

fact is revealed from a comparison of Figures 4(a) and 4(b). Figure 4(a) moreover shows that the low-temperature cross sensitivity profile is virtually the same as that observed on hydrogen-terminated diamond (HD), that is, a completely dissimilar gas sensing material. Although due to the different kinds of charge carriers (p-type in the case of HD and ntype in case of MOX, see also Section 4.1) the actual sensor response points in opposite directions, the cross sensitivity profile with regard to different analyte gases, however, is exactly the same. This latter observation paved the way for the idea that a completely new gas sensing mechanism might be involved at room temperature and slightly above [32-35].

Comparing the low- and the high-temperature gas sensing effects, it is evident that the low-temperature gas response is comparatively small and limited to a much smaller number of gases than the high-temperature one. 


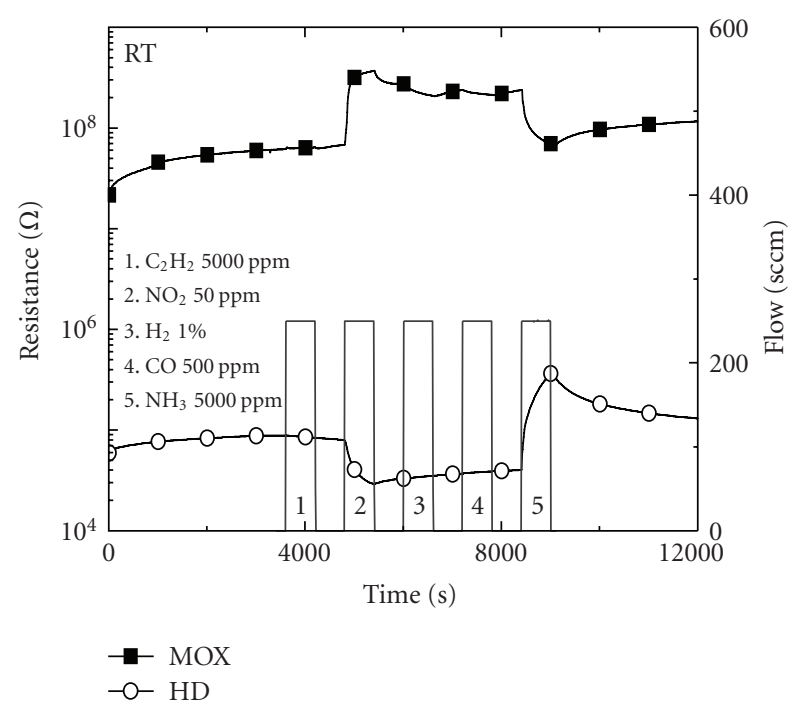

(a)

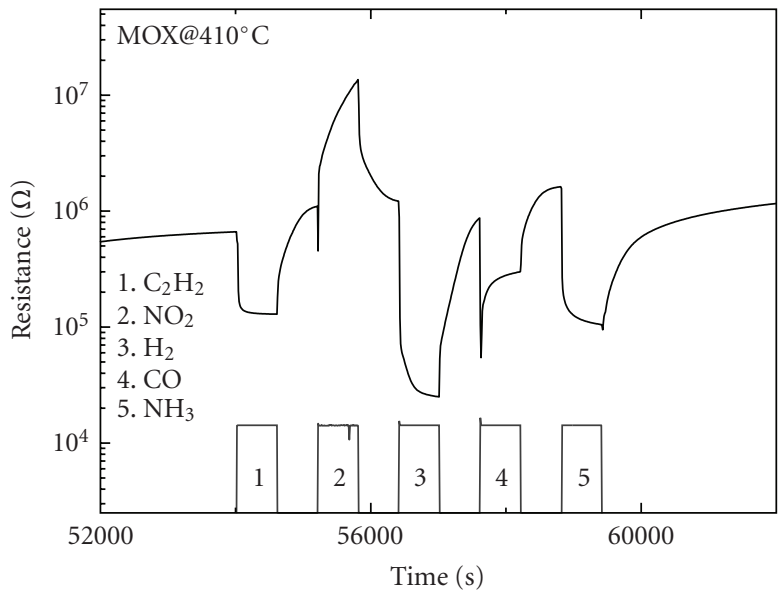

(b)

FIGURE 4: Low-temperature gas response of an $\mathrm{SnO}_{2}$ :Au sensor to a number of reducing analyte gases: (a) as measured at room temperature, (b) as measured at the normally employed high sensor operation temperatures $\left(T_{s}=400^{\circ} \mathrm{C}\right)$. The comparison in the left panel shows that $\mathrm{SnO}_{2}$ :Au and $\mathrm{HD}$ show the same kind of cross sensitivity profiles despite of their very different semiconductor surface properties [32].

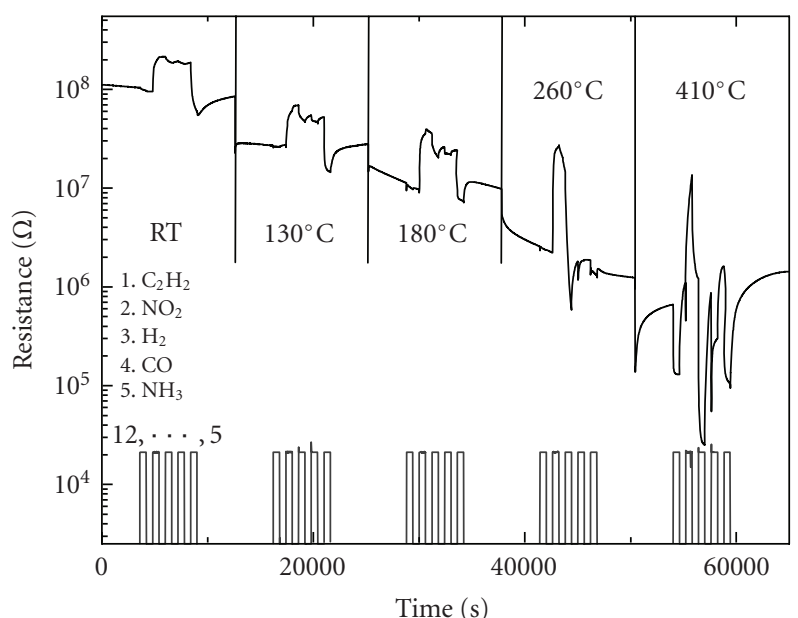

Figure 5: Transition from the low-temperature to the hightemperature gas response as the sensor operation temperature is increased from room temperature to about $400^{\circ} \mathrm{C}$ [32]. The data have been obtained on the same $\mathrm{SnO}_{2}$ :Au gas sensor as in Figure 4.

Notable examples for a comparatively high low-temperature gas sensitivity are the responses towards $\mathrm{NH}_{3}$ and $\mathrm{NO}_{2}$. A second relevant observation is that the response to both gases exhibits a huge asymmetry with regard to the response and recovery time constants: whereas response times are moderate, recovery times are extremely long.

Further clues to the nature of the low-temperature gas sensing effect can be obtained by observing changes in the gas response patterns when the operation temperature of the $\mathrm{SnO}_{2}$ :Au gas sensors is increased, as displayed in Figure 5. These data demonstrate that the low-temperature gas response pattern starts to disappear at temperatures

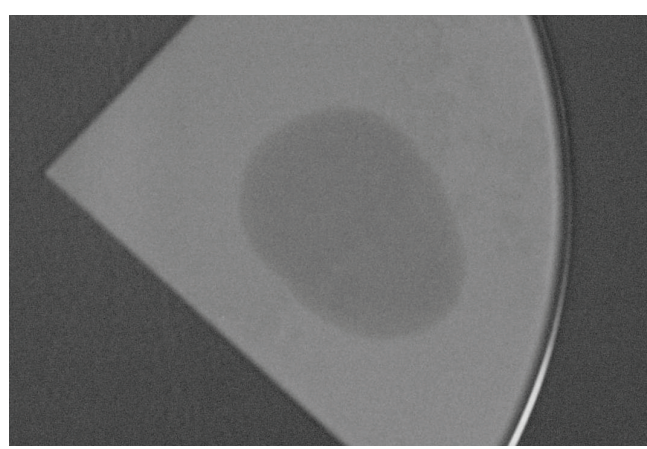

FIGURE 6: Result of a contact angle experiment as performed on a nanogranular $\mathrm{SnO}_{2}$ film deposited on an oxidised silicon wafer [32].

around $200^{\circ} \mathrm{C}$, and that it is replaced by the familiar broad-range high-temperature gas sensitivity which becomes dominant at temperatures around $400^{\circ} \mathrm{C}$.

Comparing the low-temperature MOX and HD gas sensing effects and realising that both the p-type surface conductivity and the gas response of $\mathrm{HD}$ are due to a thin layer of adsorbed water on the diamond surface [36], a similar effect was suggested for MOX materials as well. Further evidence in favour of an adsorbed liquid electrolyte layer on MOX surfaces came from the observation that MOX surfaces are fairly hydrophilic. This latter fact is evidenced in Figure 6, showing that a drop of water suspended on a MOX surface spreads out rapidly, reducing the contact angle to almost zero.

Accepting the possibility that a closed liquid electrolyte layer might indeed exist at the MOX surface, the observed low-temperature cross sensitivity profiles can be explained as follows: the MOX surface and thus the semiconductor 
band bending can only be affected once analyte molecules are dissolved in the surface water layer and dissociated there. Overall, this amounts to an indirect sensing mechanism which limits the role of the MOX layers towards that of a $\mathrm{pH}$ sensor [40]. Before we follow this idea further, we present some theoretical background that allows multilayer water adsorption phenomena on low-temperature solid surfaces to be analysed.

\section{Multilayer Water Adsorption at Solid Surfaces}

3.1. BET Isotherm. Multilayer adsorption of gases on solid surfaces is described by the BET isotherm. This isotherm was first introduced by Brunauer, Emmett, and Teller in 1938 [41]. The main assumptions leading to this isotherm are [42]

(i) polymolecular adsorption of spherical particles;

(ii) homogeneous surface with constant adsorption centre density;

(iii) the heat of adsorption of the first adsorbed monomolecular layer drops to the heat of liquefaction for all following layers;

(iv) all following polymolecular layers act like a liquid;

(v) the number of adsorbate layers can reach infinity.

With these assumptions the relative surface coverage $\Theta(T, P)$ is obtained:

$$
\Theta(P, T)=\left(\frac{P}{P_{0}(T)-P}\right) \cdot\left[\frac{c(T)}{1+\left(\frac{P}{P_{0}(T)}\right) \cdot(c(T)-1)}\right] .
$$

In this equation $P$ and $P_{0}$ represent the equilibrium and saturation vapour pressures of the adsorbate gas at the temperature $T$ and $c(T)$ of the BET constant:

$$
c(T)=\exp \left(\frac{\varepsilon_{1}-\varepsilon_{L}}{k_{B} \cdot T}\right)
$$

In this latter equation $\varepsilon_{1}$ and $\varepsilon_{L}$ represent the heats of adsorption and liquefaction, respectively.

A particularly simple form of the BET isotherm is obtained in case the first layer is adsorbed as tightly as all the others. Then $c(T)=1$ and the expression for the BET isotherm reduces to

$$
\Theta(P, T)=\frac{P}{P_{0}(T)-P} .
$$

For any vapour pressure $P$ there exists a temperature $T_{\text {sat }}$ at which the vapour pressure $P$ in the air equals the saturation pressure $P_{0}\left(T_{\mathrm{sat}}\right)$. At all temperatures $T$ lower than $T_{\text {sat }}$, the maximum vapour pressure $P(T)$ is limited by the saturation pressure at that temperature, that is, $P(T)=P_{0}(T)$. Equation (3) then predicts that under conditions of saturated water vapour, that is, at $T \leq T_{\text {sat }}$, a solid surface will adsorb infinitely many layers of water and thus form a closed layer of condensed water on the surface. For temperatures higher

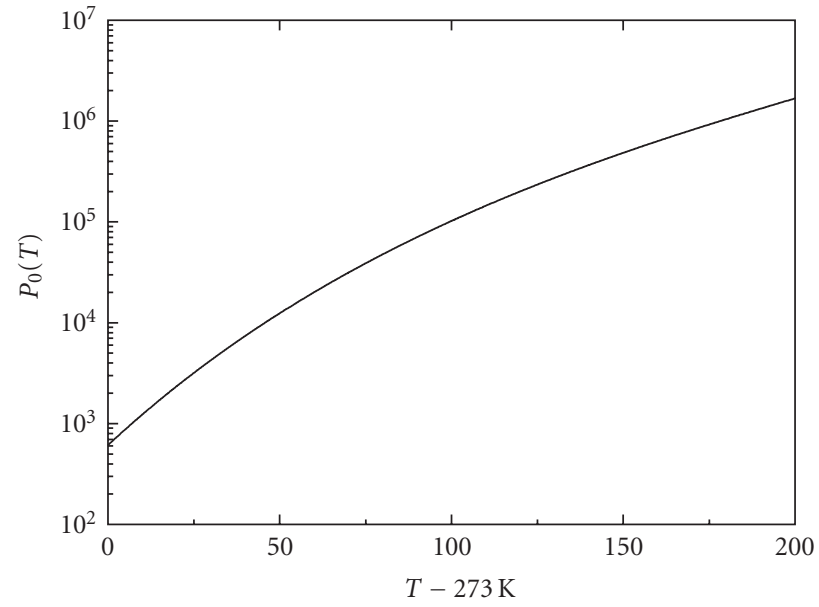

FIGURE 7: Saturation vapour pressure of water as a function of the temperature in the air.

than $T_{\text {sat }}$, the water vapour pressure in the air is supplylimited and lower than $P_{0}(T)$. In this limiting case, $P$ is much smaller than $P_{0}(T)$, and the BET equation reduces to the familiar Langmuir isotherm [43]:

$$
\Theta(P, T)=\frac{c(T) \cdot P}{c(T) \cdot P+P_{0}(T)} .
$$

As $P_{0}(T)$ increases exponentially with temperature, the surface coverage $\Theta(T, P)$ in this temperature range drops exponentially as the temperature is increased beyond $T_{\text {sat }}$.

3.2. Water Adsorption at Solid Surfaces. Considering the main constituents of the ambient $\operatorname{air}\left(\mathrm{N}_{2}, \mathrm{O}_{2}, \mathrm{H}_{2} \mathrm{O}\right.$, and $\left.\mathrm{CO}_{2}\right)$ as well as the range of analyte gases that have frequently been studied in gas sensing experiments, water vapour is outstanding insofar as it can occur in high concentrations (Figure 7) and at the same time exhibits a high boiling point (Figure 8(a)) and a concomitantly high heat of vaporisation (Figure 8(b)). Because of these properties, adsorbed water vapour can easily undergo multilayer adsorption leading to thin liquid electrolyte layers on solid surfaces, and it thus can completely alter the gas-surface interactions that may occur on a semiconductor surface.

In order to estimate the water coverage on a semiconductor surface using the BET equation, an estimate of the BET constant (2) is required. The value of this constant depends on two parameters: (i) the heat of liquefaction $\varepsilon_{L}$ and (ii) the heat of adsorption $\varepsilon_{1}$. The heat of liquefaction of water is known from literature $\left(\varepsilon_{L}=0.424 \mathrm{eV}\right.$ per molecule [45]). The heat of adsorption describes the adsorption energy of the first monolayer on the adsorbent surface. This latter value can vary strongly with the chemical composition and the morphology of the adsorbing solid. A first estimate for the heat of adsorption of water on MOX surfaces is $0.52 \mathrm{eV}$ [44]. With $c(T)$ being known, the surface coverage of water on a MOX surface can now be obtained from (1).

Assuming that water vapour saturation in the air is reached at $30^{\circ} \mathrm{C}$, it is revealed from Figure 9 that a MOX 


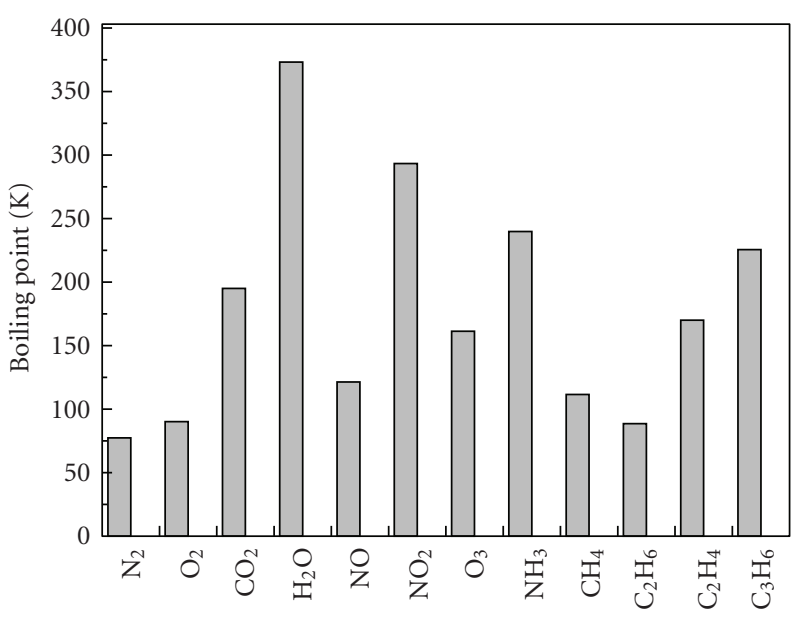

(a)

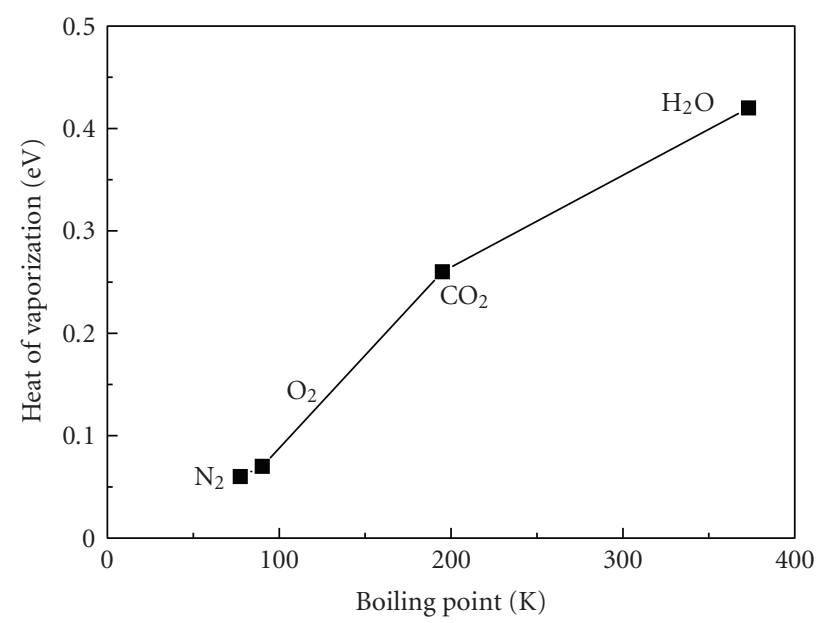

(b)

FIGURE 8: (a) Boiling points of the main air constituents and of a number of often studied analyte gas molecules; (b) heat of vaporisation of the main air constituents.

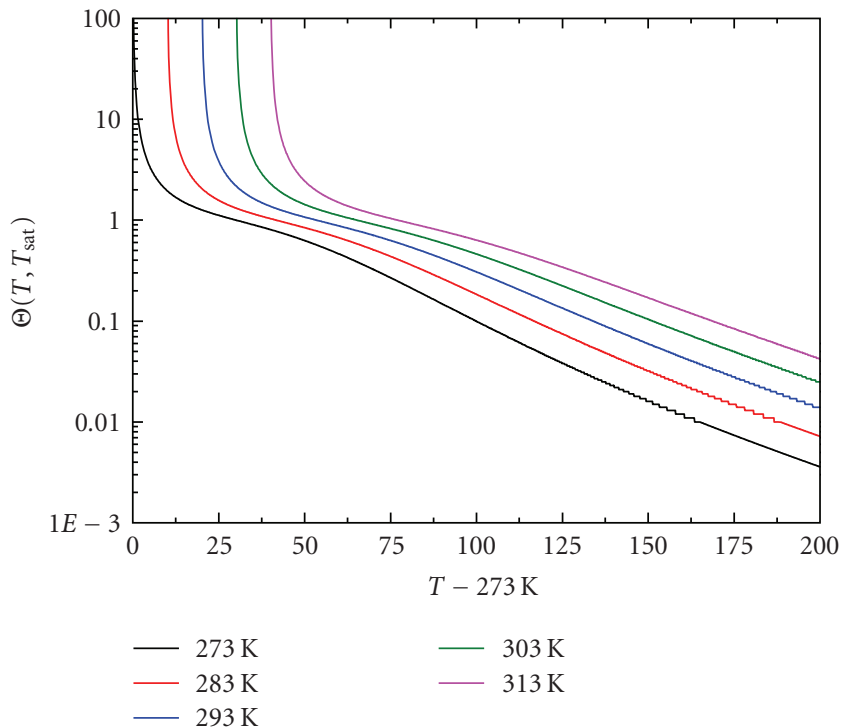

FIGURE 9: Surface coverage with water as a function of the MOX substrate temperature as evaluated from the BET isotherm. The heat of adsorption of the first monolayer was assumed to be $\varepsilon_{1}=0.52 \mathrm{eV}$ [44].

surface will always be covered by multiple layers of water as long as the substrate temperature remains at room temperature or below $\left(0<T<30^{\circ} \mathrm{C}\right)$. With a closed water film being present, oxygen surface adsorbates will not form. In case the substrate temperature is raised beyond the saturation temperature $T_{\text {sat }}$, the water surface coverage will rapidly drop into the range of a single monolayer as $T \sim 70^{\circ} \mathrm{C}$ is approached. As a single monolayer of water is sufficient to prevent oxygen ionosorption, the normal combustive detection mechanism still will not work. First indications of a combustive response, however, might be expected when there is a tendency of the adsorbed water

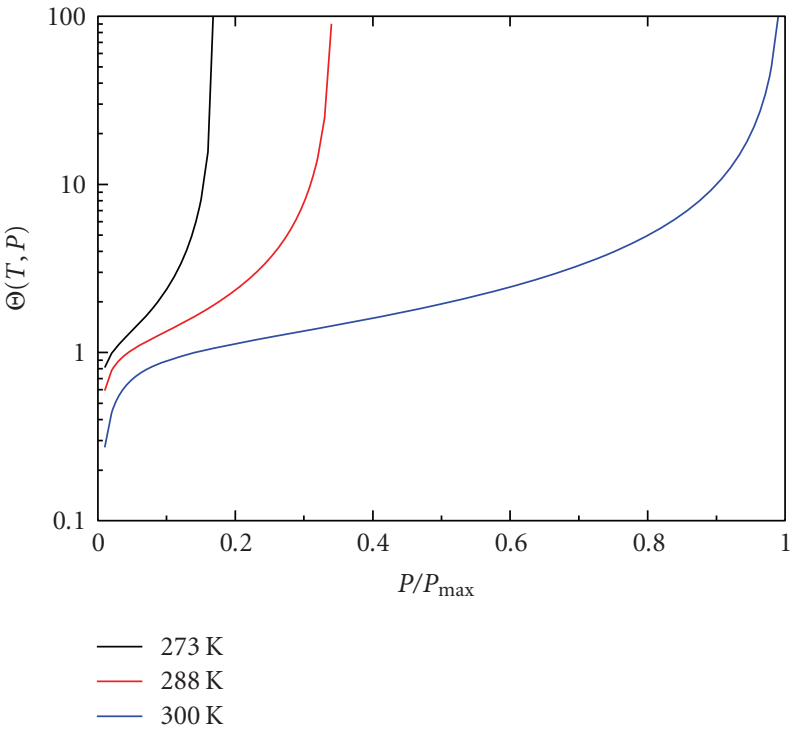

Figure 10: Water coverage as a function of vapour pressure and substrate temperature (low-temperature region $\left.T \leq T_{\text {sat }}\right)$. $T_{\text {sat }}=$ $27^{\circ} \mathrm{C}(300 \mathrm{~K})$.

to concentrate in patches with above-monolayer thicknesses. Raising the substrate temperature towards $150^{\circ} \mathrm{C}$, the water coverage drops to about 0.1 monolayers which means that large patches of free semiconductor surface start to occur, providing adsorption sites for oxygen. In agreement with this expectation we have observed that MOX gas sensors start to respond to combustible gases as this temperature is exceeded (Figure 5) and that MOX layers start to respond to changes in the humidity concentration in the gas phase (Figure 2(b)).

Figures 10 and 11 refer to two situations in which the vapour pressure in the gas phase is varied from zero to the saturation vapour pressure considering that the air 


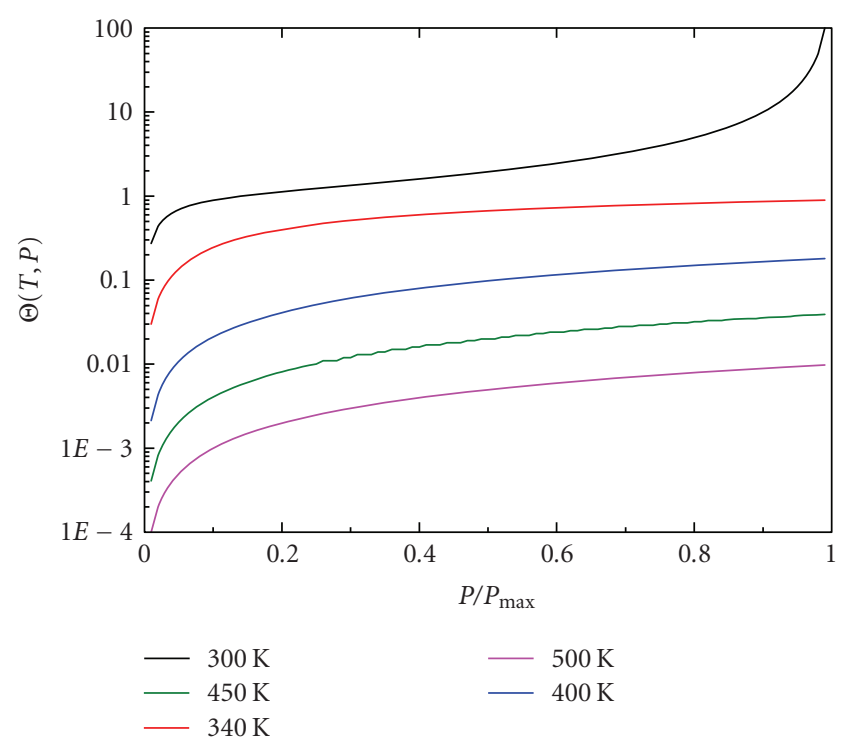

Figure 11: Water coverage as a function of vapour pressure and substrate temperature (high-temperature region $\left.T \geq T_{\text {sat }}\right) . T_{\text {sat }}=$ $27^{\circ} \mathrm{C}(300 \mathrm{~K})$.

temperature is $30^{\circ} \mathrm{C}$. The first diagram reveals that, with the MOX substrate being kept at room temperature or below, multilayer water adsorption will take place also at water vapour pressures much lower than the saturation pressure level. A normal gas response, therefore, cannot be expected in this lower $\mathrm{H}_{2} \mathrm{O}$ vapour pressure range as well. This situation changes, when the MOX substrates are heated to $150^{\circ} \mathrm{C}$ or more. In this latter case the surface water coverage varies over the entire $\mathrm{H}_{2} \mathrm{O}$ pressure range and remains in the submonolayer range. In such situations oxygen ionosorption and a normal combustive gas response can occur, and, in addition, single $\mathrm{H}_{2} \mathrm{O}$ molecules may directly adsorb on the MOX surface and thus give rise to a water-vapour-dependent response signal.

\section{The Universality of the Low-Temperature Gas Response}

The considerations in Sections 2 and 3 have indicated that a thin layer of condensed humidity might play an important role in determining the gas sensing properties of MOX gas sensors operated at or slightly above room temperature. In this paragraph we present the results of gas sensing experiments on alternative semiconductor materials which are known to carry condensed water layers on their surfaces under such moderate operation temperatures.

4.1. Hydrogen-Terminated Diamond (HD). Diamond with a bandgap of $5.5 \mathrm{eV}$ is a bona-fide insulator in its undoped state. However, it has been shown that it can exhibit a pronounced p-type surface conductivity of up to $10^{-5} \Omega^{-1}$ per square when the surface is terminated with hydrogen [46, 47]. The best established model to explain this phenomenon is the transfer doping model of Maier et al. [36]. According to these authors, a near-surface hole accumulation layer with carrier densities in the range of $10^{12}-10^{13} \mathrm{~cm}^{-2}$ forms via a transfer of diamond valence electrons to an adsorbed surface electrolyte layer. This effect, whose exact microscopic origin is still under debate, has already been employed for devices such as field effect transistors [48], single-hole transistors [49], or pH-sensors [50]. The interest in this present context is that similar devices also support gas sensing interactions that are strikingly similar to those found in room-temperature operated MOX gas sensors.

The investigated samples are shown in Figure 12. The left-hand side of this figure is a sketch of our present state of understanding of surface transfer doping in HD [36]. The essential information of this sketch is that a very thin surface p-type layer in the H-terminated diamond is formed when diamond valence electrons are transferred to $\mathrm{H}_{3} \mathrm{O}^{+}$ ions into the adsorbed liquid electrolyte layer. In the course of this transfer a fraction of the $\mathrm{H}_{3} \mathrm{O}^{+}$ions is neutralised forming $\mathrm{H}_{2} \mathrm{O}$ and $\mathrm{O}_{2}$ molecules, the latter being emitted to the gas phase. In summary, a negative excess charge arises in the liquid electrolyte layer which is compensated by the surface hole accumulation layer in the diamond. Analyte gas molecules with the capability of dissolving and undergoing electrolytic dissociation can disturb this charge equilibrium and thus promote conductance changes, which have been monitored using the device structure presented in the righthand part of Figure 12. In this device $\mathrm{Ti} / \mathrm{Au}$ electrodes $(20 \mathrm{~nm} / 200 \mathrm{~nm})$ were applied in a gap cell configuration to probe the surface conductivity of the diamond. The contact pad area was $1000 \mu \mathrm{m} \times 230 \mu \mathrm{m}$, and the spacing between the contacts was $1000 \mu \mathrm{m}$. Prior to the electrode deposition the diamond surface was processed in a way as to obtain an $\mathrm{H}$-terminated surface in between the Ti/Au electrodes and an O-terminated surface in the periphery of the gap cell $[33,34]$.

Figures 13 and 14 present key results of the related gas sensing experiments.

Figure 13(a) can be regarded as a mirror image of the respective results for room-temperature operated MOX gas sensors (see also Figure 4(a)). Due to the fact that holes are the majority carriers in $\mathrm{HD}$, we observe a resistivity decrease upon exposure to $\mathrm{NO}_{2}$ and an increase upon exposure to $\mathrm{NH}_{3}$. The insensitivity towards $\mathrm{C}_{2} \mathrm{H}_{4}, \mathrm{H}_{2}$, and $\mathrm{CO}$, that is, towards a representative range of combustible gases, is demonstrated by the zero response towards $\mathrm{C}_{2} \mathrm{H}_{4}$ and the undisturbed long recovery from the $\mathrm{NO}_{2}$ exposure during exposure to $\mathrm{H}_{2}$ and $\mathrm{CO}$. The long $\mathrm{NO}_{2}$ recovery is terminated by the final exposure to $\mathrm{NH}_{3}$. As $\mathrm{NH}_{3}$ was added in excess to the $\mathrm{NO}_{2}$, a conductivity effect of opposite sign is created and still persists a long time after the termination of the $\mathrm{NH}_{3}$ pulse. The other effect that is demonstrated in Figure 13(a) is that dilution of the hole gas by a partial conversion of $\mathrm{H}$ termination to O-termination sites increases the gas sensitivity without altering the cross sensitivity profile. This latter effect was attributed to a catalytic effect of the O-termination sites in converting electronic into ionic charge and vice versa when charge carriers cross the semiconductor/liquid electrolyte interface [34, 37].

Figure 13(b) summarises the results of $\mathrm{NO}_{2}$ and $\mathrm{NH}_{3}$ gas sensing experiments in a plot of gas response versus 


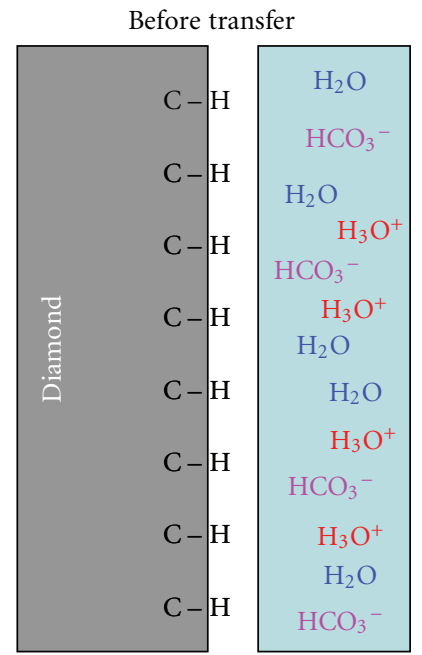

(a)

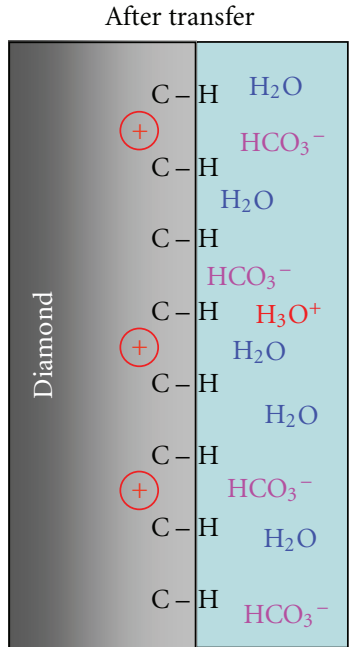

)

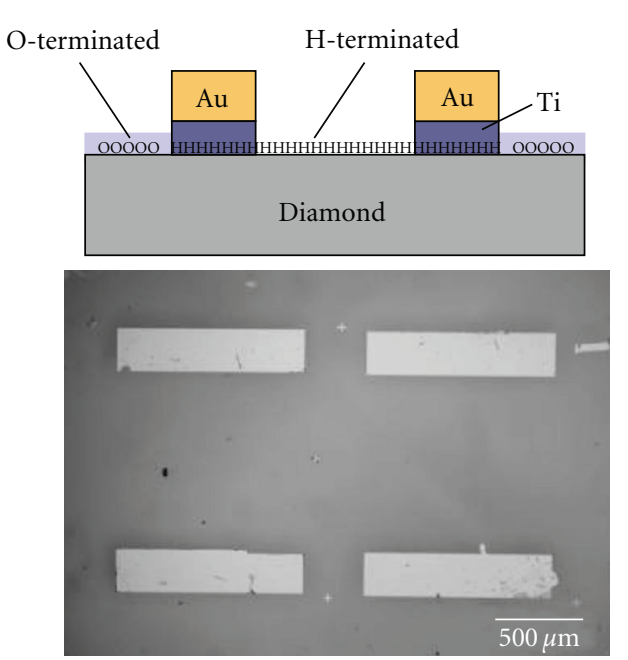

(b)

Figure 12: (a) Transfer of valence electrons from the diamond surface to an adsorbed liquid electrolyte layer according to Maier et al. [36]. The adsorbed water layer is assumed to be slightly acid due to the dissolution of atmospheric $\mathrm{CO}_{2}$; (b) cross section through a hydrogen terminated diamond sensor (top) and onto a processed device (bottom).

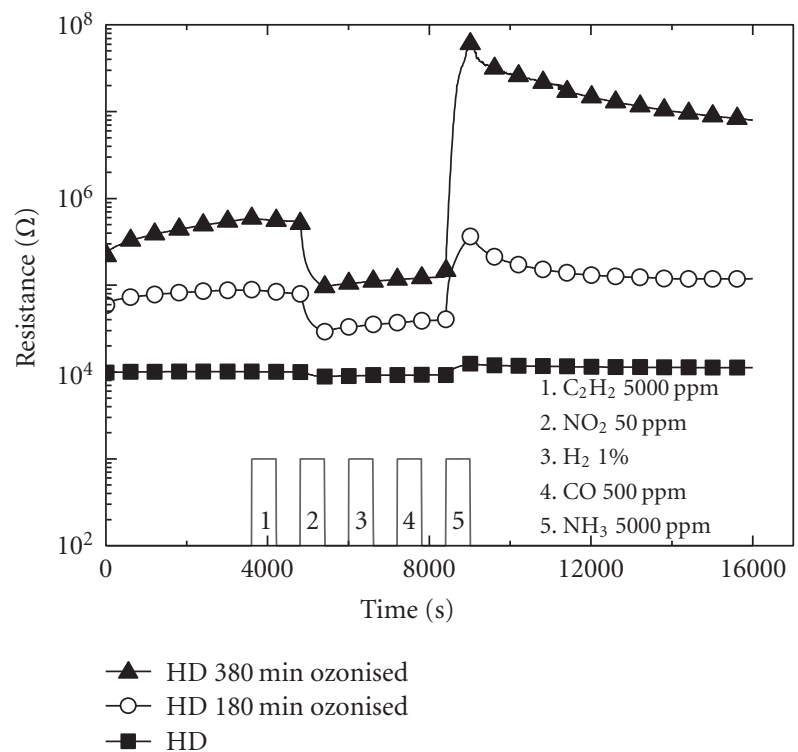

(a)

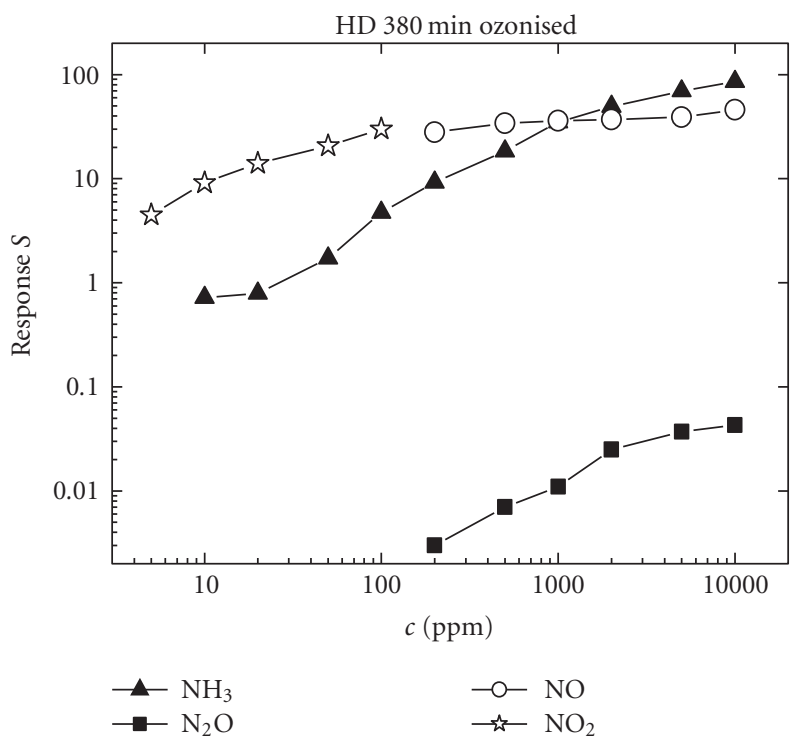

(b)

FIGURE 13: (a) Response of an HD sample, processed to exhibit different baseline resistances, towards a representative range of analyte gases; (b) concentration-dependent response of a hydrogen-terminated diamond sample towards different nitrogen bearing gases. $\mathrm{NO}$ and $\mathrm{NO}_{2}$ exhibit an acidic (resistance decrease) and $\mathrm{NH}_{3}$ and $\mathrm{N}_{2} \mathrm{O}$ a basic (resistance increase) response. During these tests the HD sample was kept at room temperature.

concentration. In this plot we have also included data on a wider variety of gases that led to a gas response. In all cases these are nitrogen-bearing gases. In a previous publication [34] we have related the different levels of sensitivity to the individual gases to their different capabilities of dissolving there as acids or bases.

Figure 14, finally, shows that the HD sensors do not respond to changes in the $\mathrm{H}_{2} \mathrm{O}$ vapour concentration in the ambient air at all. We note here that room-temperatureoperated MOX gas sensors exhibit a similar effect. A difference, however, arises when the adsorbed water layer is evaporated by increasing the sensor operation temperature: whereas in MOX gas sensors evaporation of the adsorbed humidity layer leads back to the usual combustive gas response, the surface transfer doping effect in the HD samples disappears. With the HD samples thus having 


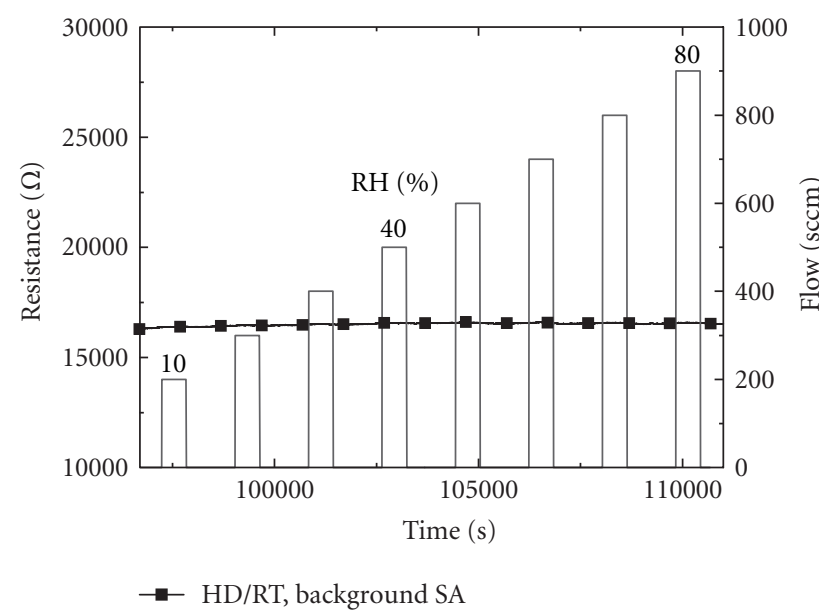

Figure 14: Response of an HD sample towards water vapour. During these tests the HD sample was kept at room temperature.

been returned to their intrinsic high-resistivity state, all gas sensitivity disappears as well until, eventually, the HD samples are rehydrated. All three semiconductor materials investigated here return to their dissociative sensing behaviour after a cycle of evaporation and readsorption of humidity at their surfaces [32-35].

The data in Figure 15 show a result of an actual test in a chemical laboratory in which an HD sensor was exposed to acid and base vapours emitted from a chemical laboratory workbench. These latter results clearly support the fact that HD sensors are able to sense acid and base vapours that dissolve in the electrolyte layer. During these experiments also the acids $\mathrm{HCl}, \mathrm{H}_{2} \mathrm{O}_{2}$, and $\mathrm{CH}_{2} \mathrm{O}_{2}$ were successfully detected.

4.2. Hydrogenated Amorphous Silicon (a-Si:H). A second semiconductor material, where the presence of adsorbed humidity layers has been confirmed, is hydrogenated amorphous silicon (a-Si:H). This material has found widespread commercial application in photovoltaic solar energy conversion and in large-area thin film electronic devices [51, 52]. In the course of these developments the basic material properties of a-Si:H have been intensively investigated [53, 54]. In this context it has been established that ambient humidity does give rise to adsorbed layers of water on aSi:H surfaces [55-57]. Furthermore, it has been shown that $\mathrm{NH}_{3}$ exposure of undoped a-Si:H films at room temperature can increase the conductance by several orders of magnitude [55]. In this early work it was argued by Tanielian and Fritzsche that misleading conclusions can be drawn about basic physical properties of a-Si:H films as long as there is uncertainty about the presence of surface adsorbates.

In the context of our present investigations we have reconsidered the phenomenon of the a-Si:H gas response, performing gas sensing tests under conditions which are more typical of gas sensor operation [35]. With regard to gas sensing tests performed at room temperature, our key results

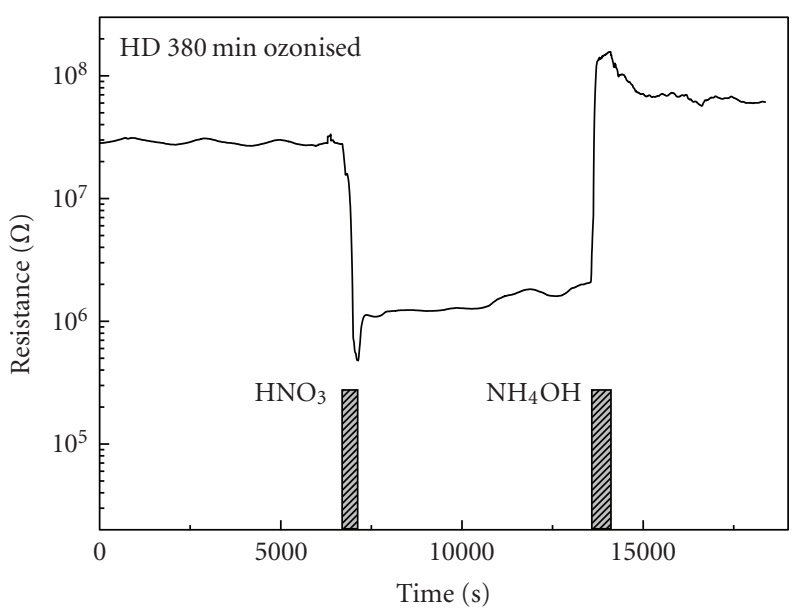

FIGURE 15: Response of an HD sample with a partially oxygenated surface towards acid and base vapours, generated in a clean-room environment.

are summarised in Figure 16. These data firstly show thatsimilar to the MOX and HD cases-a-Si:H films hardly respond to changes in the humidity content of the ambient air (Figure 16(a)). Secondly, we again observe pronounced and selective conductivity changes upon exposure towards $\mathrm{NO}_{2}$ and $\mathrm{NH}_{3}$. Thirdly, very long recovery time constants are observed after the a-Si:H films had been exposed to $\mathrm{NO}_{2}$ and particularly $\mathrm{NH}_{3}$. As already argued above, these results are consistent with the presence of an adsorbed liquid electrolyte layer at the a-Si:H surface. With regard to the MOX and HD cases, however, an important difference arises in that both $\mathrm{NO}_{2}$ and $\mathrm{NH}_{3}$ exposures lead to an increased conductance of the a-Si:H/electrolyte system. Considering the fact that undoped a-Si:H is almost intrinsic and therefore highly resistive at room temperature, it cannot be ruled out that the sensor resistance is dominated in this case by the adsorbed liquid electrolyte layer itself. In this case it is clear that opposite changes in the $\mathrm{pH}$ level of the surface electrolyte will always lead to a conductance increase of the a-Si:H/liquid electrolyte layer stack. An alternative explanation for this effect would be that $\mathrm{pH}$ changes in the surface electrolyte could either increase the small native n-type conductivity of the a-Si:H or turn its conduction from n-type to p-type. In both cases an increased conductivity would be expected upon exposure to acid-or base-forming gases.

In the a-Si:H case the firmest evidence for the existence of an adsorbed liquid electrolyte layer was obtained by operating the a-Si:H films at temperatures above the water evaporation threshold of about 150 to $200^{\circ} \mathrm{C}$. Under these conditions the results of Figure 17 have been obtained. Here we see that-similar to the MOX case-a-Si:H films do start to respond to changes in the humidity content in the ambient air.

This latter result is interesting in two respects: firstly it adds evidence to the existence of a closed adsorbed humidity layer on the a-Si:H surface at room temperature and above, and secondly it shows that a-Si:H exhibits an intrinsic bulk conduction that is independent of the presence or absence 


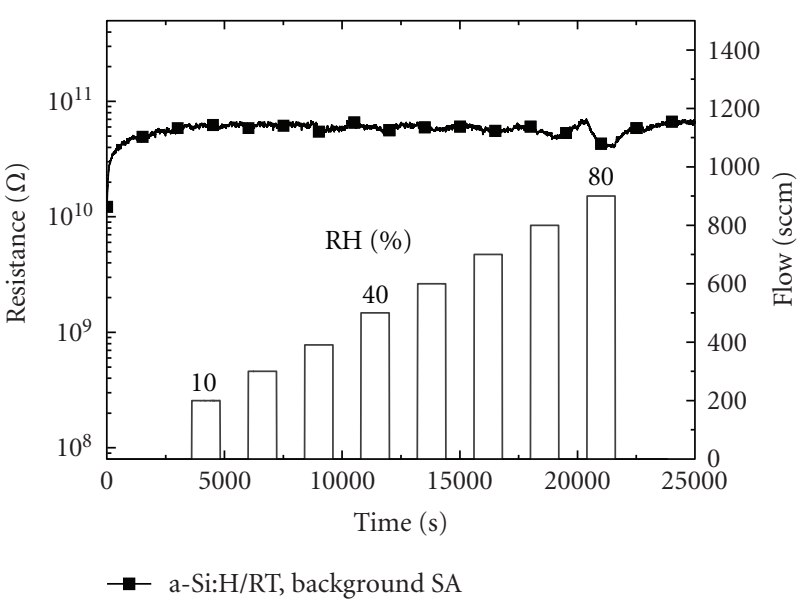

(a)

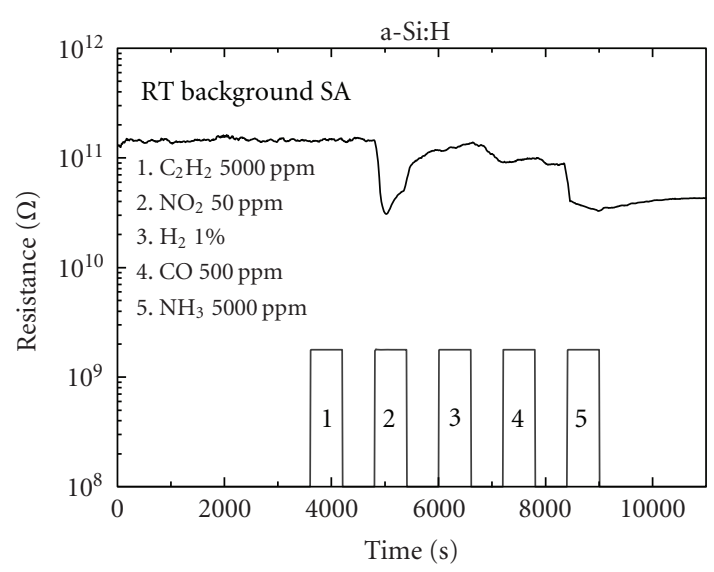

(b)

Figure 16: Resistivity response of an undoped a-Si:H film towards changes in the ambient humidity concentration (a) and towards a representative range of analyte gases (b). During these tests the a-Si:H film was kept at room temperature.

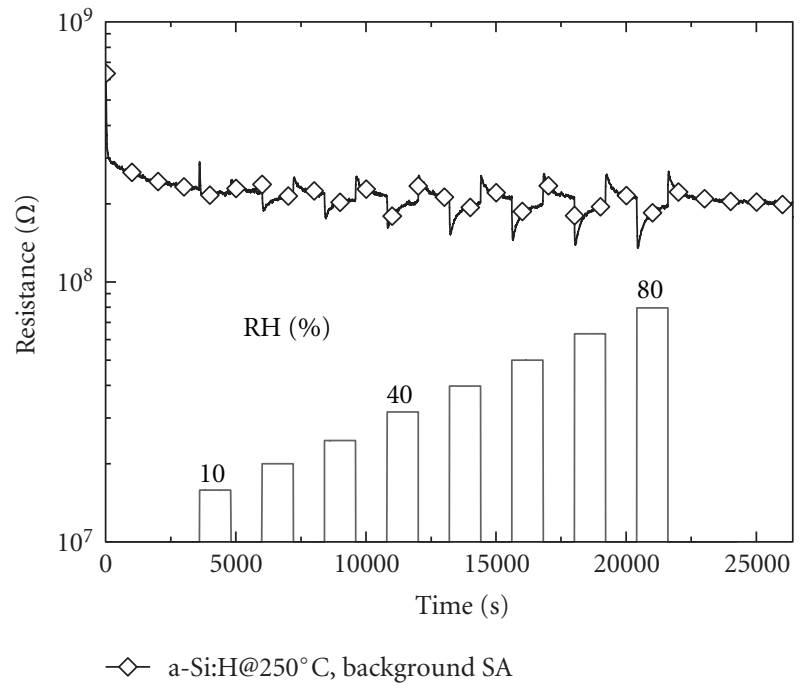

Figure 17: Response of an undoped a-Si:H film towards different concentrations of water vapour in the ambient air. Sensor operation temperature: $250^{\circ} \mathrm{C}$.

of a surface electrolyte layer. Performing gas sensing tests at $T \sim 250^{\circ} \mathrm{C}$, which is of the order of the deposition temperature of the a-Si:H films, gas response patterns can therefore be observed that are characteristic of $\mathrm{H}$-terminated sensor surfaces. Such experiments could not be performed on H-terminated diamond as a finite level of p-type surface conductivity can only be observed when a surface adsorbate is present.

Operating a-Si:H films under adsorbate-free conditions, we still do observe a sensitivity towards $\mathrm{NO}_{2}$ and $\mathrm{NH}_{3}$ (Figure 18). With regard to water-free MOX surfaces, the surprising result is that the high-temperature a-Si:H gas sensitivity is far more selective than that of MOX materials. This latter fact is demonstrated in Figure 19, which shows that a-Si:H films do respond predominantly to nitrogen- bearing gases. Gases which simply exhibit combustibility and which can easily be detected with heated MOX gas sensors such as $\mathrm{H}_{2}$ and ethene lead to a response that is two orders of magnitude smaller than the $\mathrm{NO}_{2}$ and $\mathrm{NH}_{3}$ responses. This latter kind of selectivity has been explained in our previous publication [35] on account of the fact that a-Si:H films exhibit $\mathrm{H}$-terminated surfaces that can easily interact with molecules which exhibit lone-pair orbitals like $\mathrm{H}_{2} \mathrm{O}$ and $\mathrm{NH}_{3}$ or electron-deficient three-centre orbitals like $\mathrm{NO}_{2}$. The proposed surface interactions of $\mathrm{H}_{2} \mathrm{O}$ and $\mathrm{NH}_{3}$ are illustrated in Figure 20.

\section{Response and Recovery Time Constants}

The results discussed so far have provided evidence that the room-temperature response of semiconductor gas sensors is mediated by a thin layer of condensed water. This limits the gas sensitivity to molecules which can easily dissolve and undergo electrolytic dissociation in water. A consequence of the electrolytic dissociation is that the resulting charged molecular fragments become hydrated, that is, they acquire a shell of oriented water molecules around them. This hydration effect severely reduces the reevaporation rate of the dissolved analytes back into the gas phase. Once a gas exposure pulse has been terminated, the back-reaction is therefore critically slowed down, and the sensor fails to return to baseline again. Considering potential applications of this low-temperature effect, it is therefore relevant to identify measures to decrease the recovery time constants. In the following we discuss some of these possibilities in the context of HD sensors.

5.1. Effect of Sensor Operation Temperature. A first and obvious measure is increasing the sensor operation temperature, keeping in mind the thermal stability of the surface electrolyte layer and of the H-termination of the diamond, which is the enabling factor for the surface transfer doping effect. Considering the stability of the $\mathrm{H}$-termination, we note that 


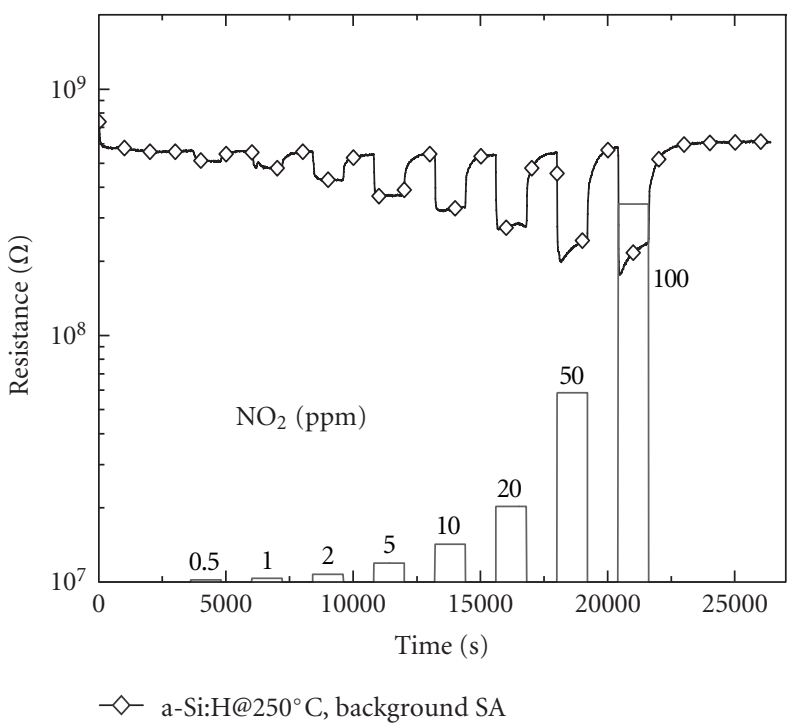

(a)

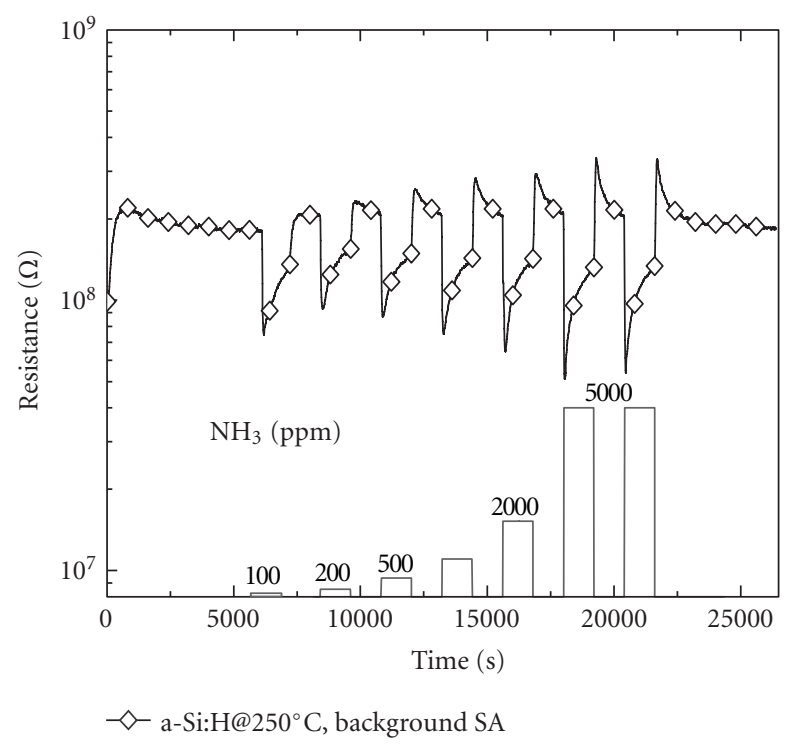

(b)

FIGURE 18: Response of an undoped a-Si:H film towards different concentrations of $\mathrm{NO}_{2}$ (a) and $\mathrm{NH}_{3}$ (b). Sensor operation temperature: $250^{\circ} \mathrm{C}$.

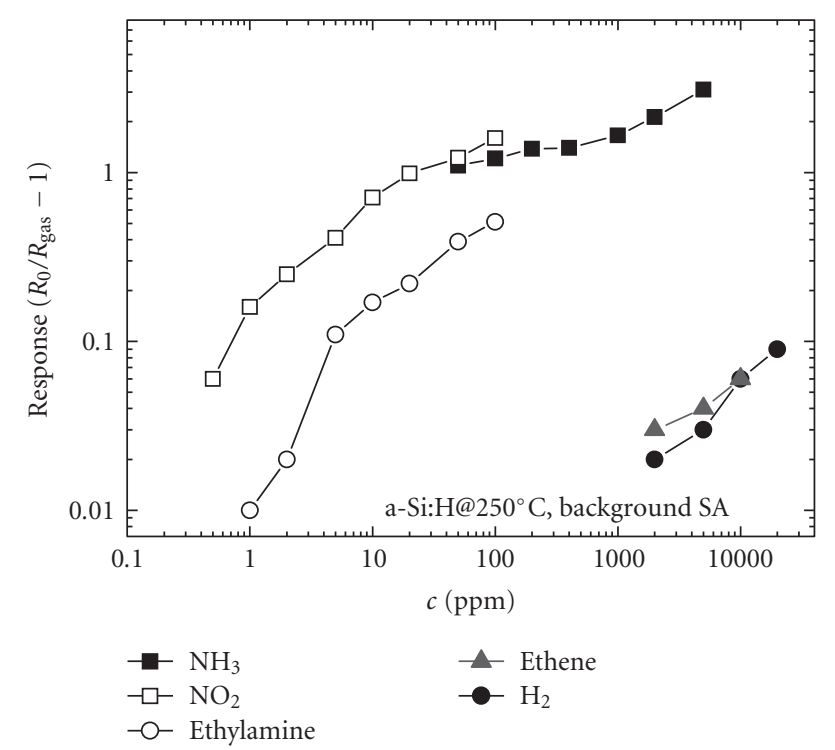

Figure 19: Response of an undoped a-Si:H film towards nitrogenand nonnitrogen bearing gases. Sensor operation temperature: $250^{\circ} \mathrm{C}$.

it is stable up to annealing temperatures in the order of $800^{\circ} \mathrm{C}$ in vacuum [58]. The adsorbed surface electrolyte, the second requirement for the formation of a hole accumulation layer, is less stable. Electrolyte desorption was already observed at temperatures above $150^{\circ} \mathrm{C}[34,50]$. Respecting these much more rigid temperature constraints, we have performed gas sensing tests up to surface temperatures of $140^{\circ} \mathrm{C}$. Within the temperature interval from room temperature up to $140^{\circ} \mathrm{C}$, we did not find any significant changes in the cross sensitivity behaviour. The main difference was that those gases that

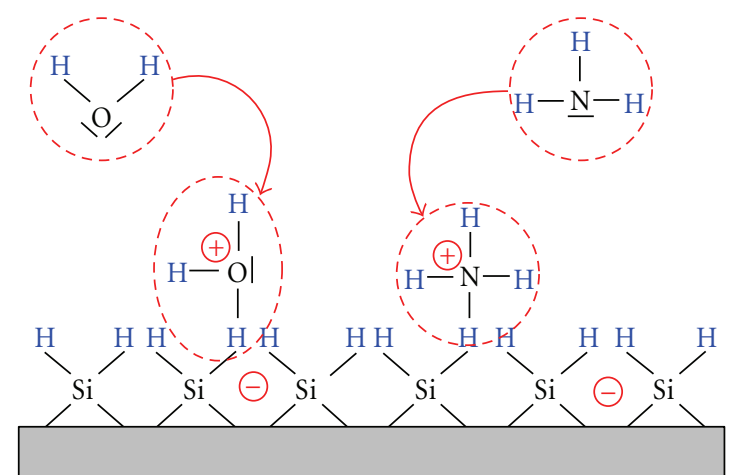

Figure 20: Proposed interaction of $\mathrm{H}_{2} \mathrm{O}$ and $\mathrm{NH}_{3}$ molecules on a water-free a-Si:H surface.

could be detected exhibited a faster response and recovery behaviour than at room temperature. This fact is illustrated in Figure 21, considering the special case of response to $\mathrm{NH}_{3}$. These data show that both the response and recovery time constants decrease with increasing sensor operation temperature. As a second effect, we observe a reduction in the magnitude of the steady-state gas response. Compared to MOX materials, however, this temperature effect is quite small [59].

5.2. Effect of UV Light Exposure. The beneficial effect of UV light exposure on the response and recovery time is illustrated in Figure 22. Here, the transient response of an HD sample with a partially oxidised surface to two successive $\mathrm{NH}_{3}$ pulses is shown. During the first gas pulse, light from a UV LED $(\lambda \sim 255 \mathrm{~nm})$ was used to irradiate the HD surface. Before the $\mathrm{NH}_{3}$ exposure pulse the UV light decreased the baseline resistance of the sensor by roughly 


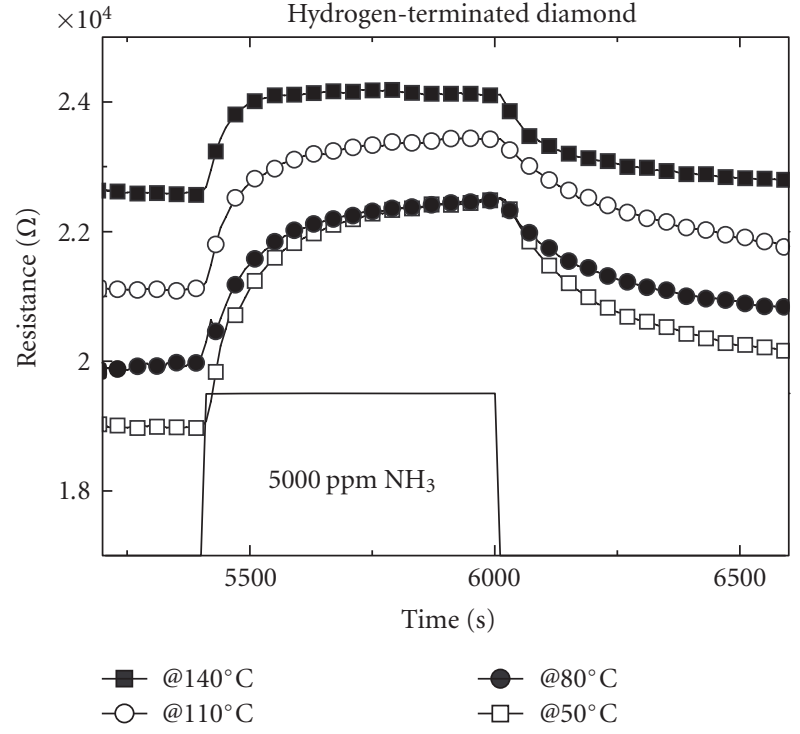

Figure 21: Response of a hydrogenated HD sample towards $\mathrm{NH}_{3}$ gas pulses. In this experiment the HD sample was operated at successively higher temperature.

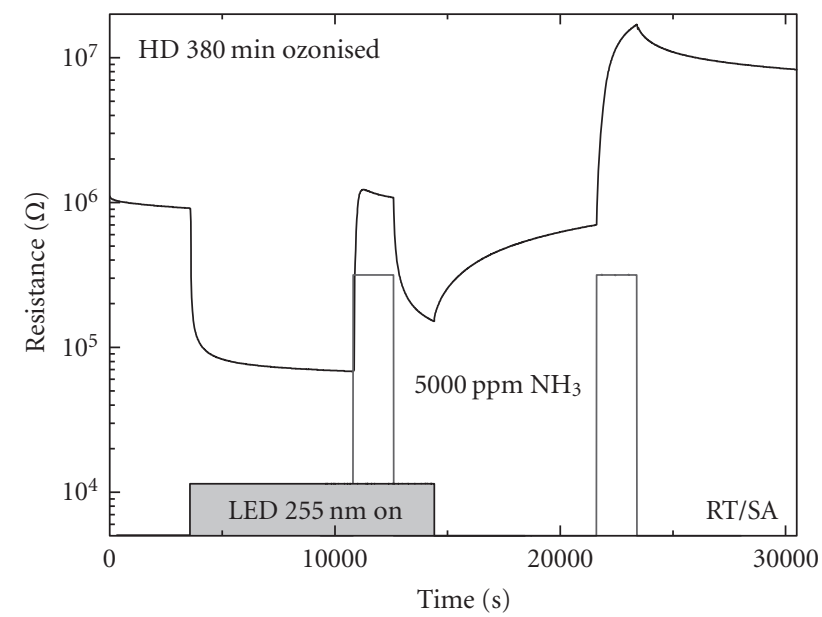

FIGURE 22: Response of an HD sample with a partially oxidised surface towards two $\mathrm{NH}_{3}$ exposure pulses. During the first pulse the HD sample was illuminated with UV light.

one order of magnitude. Upon $\mathrm{NH}_{3}$ exposure, a significantly shorter response time is observed as compared to the second exposure pulse, that was carried out in the dark. When the UV illumination was continued beyond the $\mathrm{NH}_{3}$ exposure pulse, the UV light also lead to a decrease of the recovery time constant.

5.3. Effect of Ozone Exposure. The exposure to ozone further proved to be successful in the case of $\mathrm{NH}_{3}$ detection. $\mathrm{O}_{3}$ is heavily oxidising and can therefore be detected in $\mathrm{ppb}$ $\left(10^{-9}\right)$ concentrations at heated MOX surfaces. In contrast, $\mathrm{O}_{3}$ did not produce any gas response on room-temperatureoperated HD gas sensors. However, as shown in Figure 23,

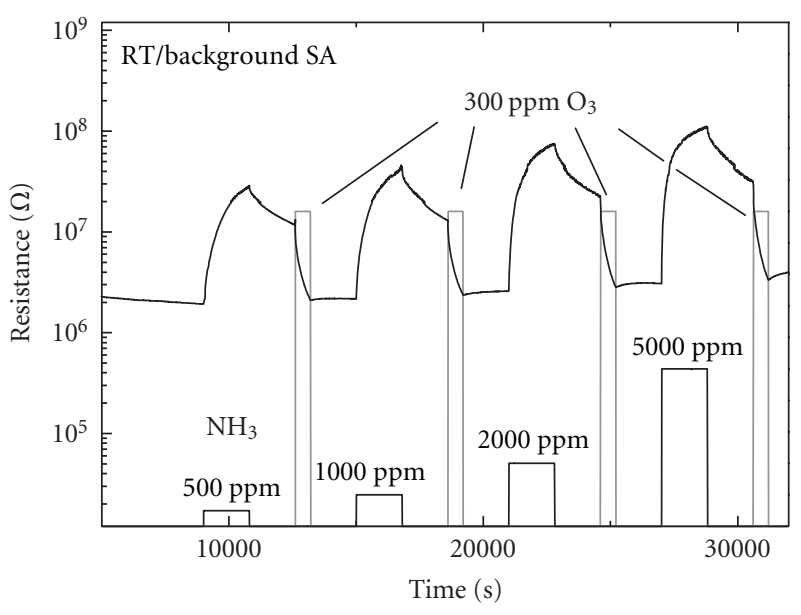

FIGURE 23: Response of an HD sample towards increasing $\mathrm{NH}_{3}$ concentration steps. The short $\mathrm{O}_{3}$ exposure pulses following each $\mathrm{NH}_{3}$ exposure pulse demonstrate the $\mathrm{O}_{3}$-induced resetting of the sensor surface to baseline. During these tests the HD sample was kept at room temperature.



Figure 24: Semiconductor materials and temperature ranges which support the different kinds of sensing characteristics.

there was a huge effect when the $\mathrm{O}_{3}$ was employed after an $\mathrm{NH}_{3}$ exposure pulse.

A possible explanation for this latter effect is the wellknown ozone oxidation reaction of $\mathrm{NH}_{3}$ :

$$
2 \mathrm{NH}_{3}+4 \mathrm{O}_{3} \longrightarrow \mathrm{NH}_{4} \mathrm{NO}_{3}+4 \mathrm{O}_{2}+\mathrm{H}_{2} \mathrm{O} .
$$

The resulting ammonia nitrate can disintegrate into $\mathrm{NH}_{4}{ }^{+}$and $\mathrm{NO}_{3}{ }^{-}$ions again and thus produce opposing $\mathrm{pH}$ changes in the surface electrolyte, that is, re-establish neutrality again. As short-wavelength UV light can produce ozone, this latter reaction might also contribute to the UV acceleration effect.

\section{Sensing Mechanisms}

6.1. Semiconductors and Sensor Operation Temperature Ranges. In the previous sections we have presented the results of gas sensing tests on three different kinds of semiconductor materials: a first group of MOX materials where oxygen is the chemically reactive species at the sensor surface and a second group of materials, $\mathrm{HD}$ and a-Si:H, which both expose covalent, $\mathrm{H}$-terminated $\mathrm{C}-\mathrm{H}$ or $\mathrm{Si}-\mathrm{H}$ bonds to the gas ambient. We have firstly shown that, irrespective of the chemical properties of the sensor surface, all kinds of semiconductor materials exhibit largely the 


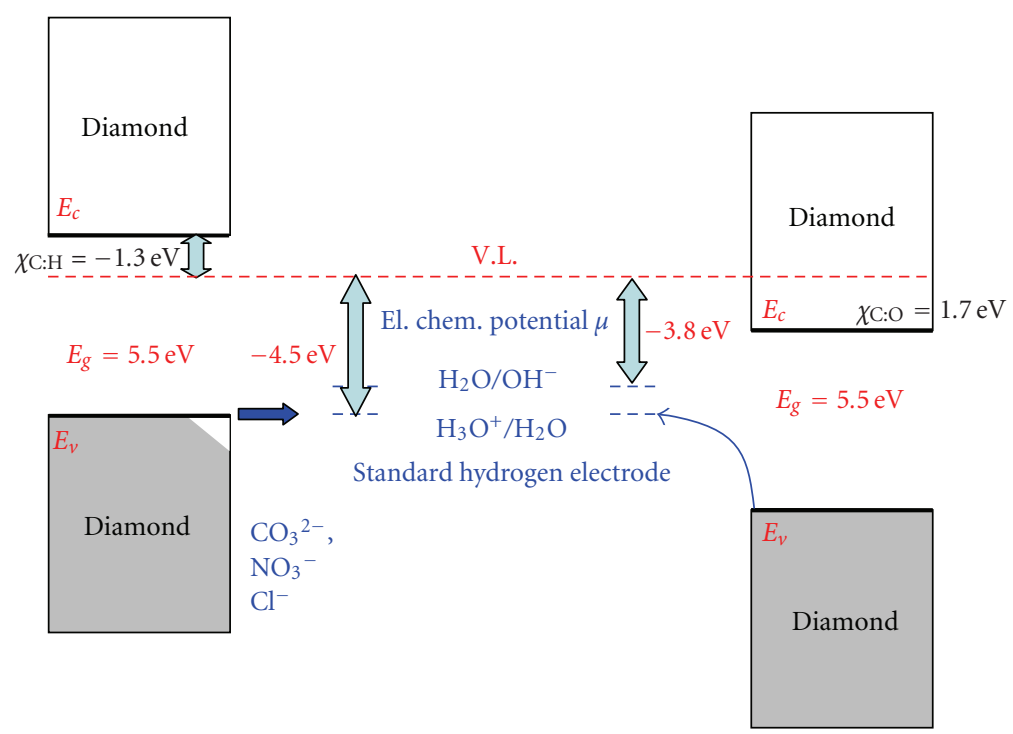

FIGURE 25: Position of the valence and conduction bands of $\mathrm{H}$-terminated diamond (left) and O-terminated diamond (right) relative to the $\mathrm{H}_{3} \mathrm{O}^{+} / \mathrm{H}_{2} \mathrm{O}$ and $\mathrm{H}_{2} \mathrm{O} / \mathrm{OH}^{-}$redox levels in water (middle). The energetic match of the $\mathrm{H}_{3} \mathrm{O}^{+} / \mathrm{H}_{2} \mathrm{O}$ redox level in water with the top of the valence band in $\mathrm{H}$-terminated diamond facilitates the transfer of diamond valence electrons into the surface electrolyte and thus the formation of a p-type surface layer in undoped diamond.

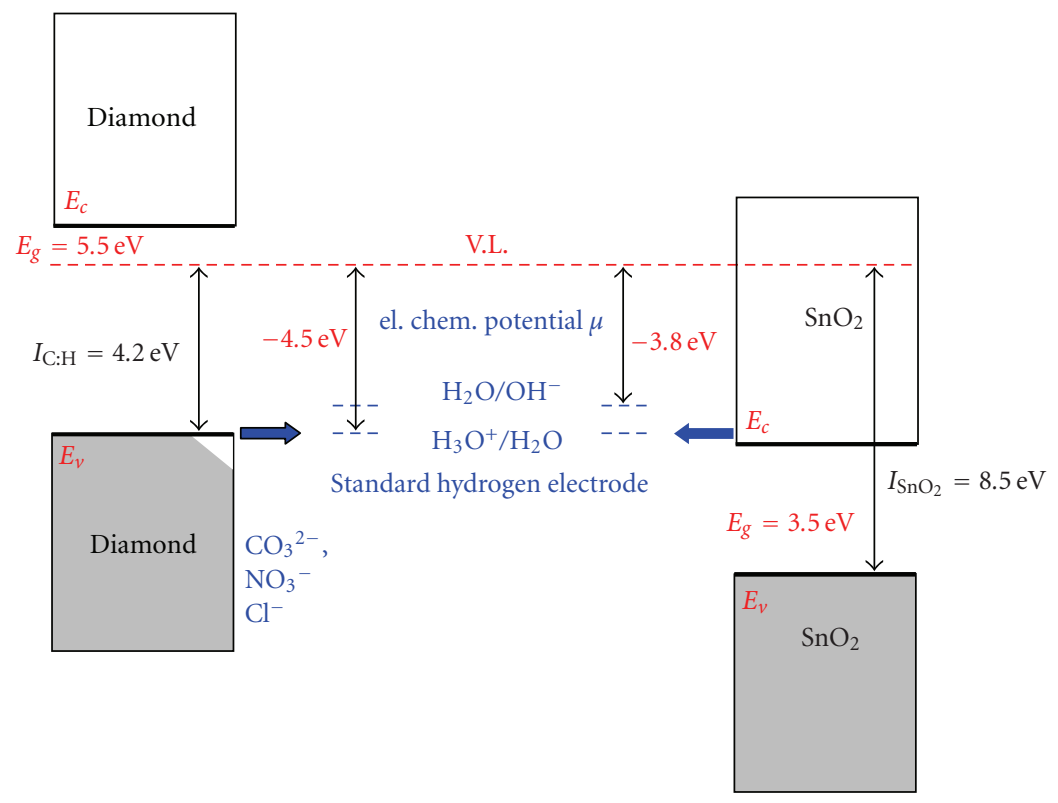

FIGURE 26: Energetic conditions at HD/liquid electrolyte and MOX/liquid electrolyte interfaces. V.L. denotes the vacuum level.

same kind of dissociative room-temperature gas response. Secondly, we have shown that at higher-temperatures, where closed adsorbed humidity layers can no longer exist, the different chemical composition of the sensor surfaces starts to matter giving rise to different kinds of sensor response. For clarity, this situation is visualised in Figure 24, defining once more the names that we have given to the different kinds of sensor response.

Among the sensing mechanisms mentioned, the combustive MOX effect has amply been considered and needs no further discussion here $[2,8,38,60-63]$. The coordinative effect, observed on water-free a-Si:H surfaces, is certainly a very innovative effect and of interest both from an application and a basic-science point of view. Clearly, however, with the very few data available at the moment, it is too early to arrive at definite conclusions yet. In the following we discuss the dissociative gas sensing effect in more detail, as it is universally observed at room temperature or slightly above on all three kinds of semiconductor materials investigated here. Trying to understand this latter effect is made possible 


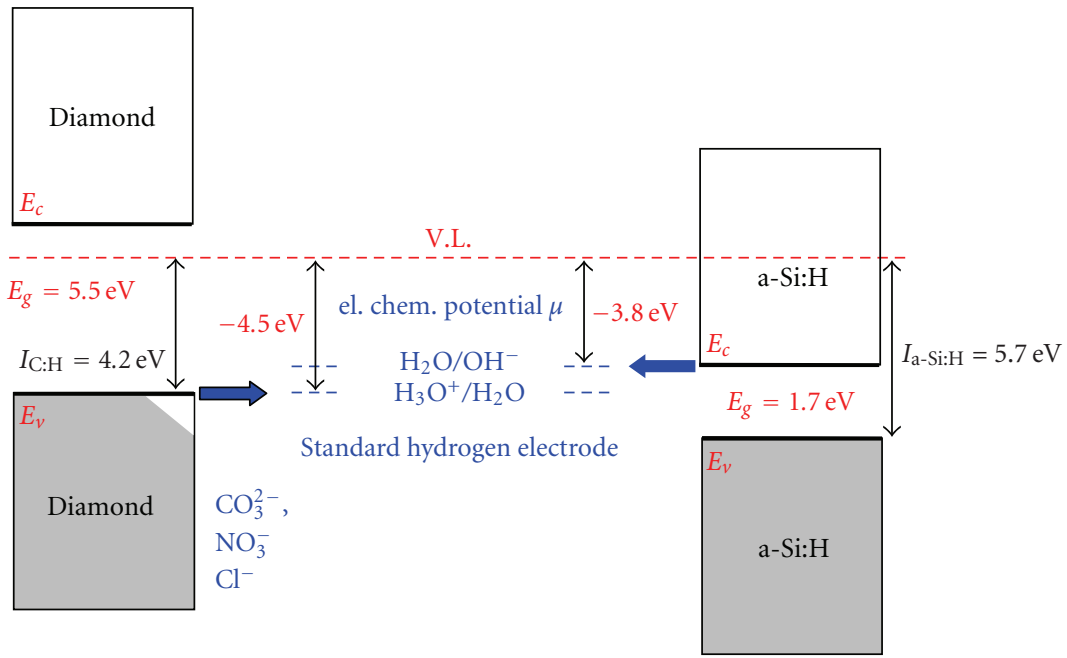

FIgURE 27: Energetic conditions at HD/liquid electrolyte and a-Si:H/liquid electrolyte interfaces. V.L. denotes the vacuum level.

by the following favourable situation: firstly there is a firm scientific basis that allows gas/liquid electrolyte interactions to be discussed and, secondly, there is a well-investigated model system where electronic interactions between an adsorbed liquid electrolyte layer and an underlying semiconductor substrate have been investigated. This model system is the $\mathrm{HD} /$ liquid electrolyte system. Trying to understand the universality of the low-temperature dissociative gas response, the common aspect of the gas/liquid electrolyte interaction needs to be considered, and then mechanisms need to be identified which explain how the gas-induced electrochemical changes in the surface electrolyte are communicated to the different semiconductor substrates.

6.2. Gas/Electrolyte Interactions. With a liquid electrolyte layer existing at the sensor surface, the first obvious step in the sensing mechanism is the penetration of the analyte gases into the liquid and absorption there. Considering those gases where we have detected a significant gas response in the liquid electrolyte/HD system, we have proposed that absorption in the liquid is followed by electrolytic dissociation and concomitant changes in the concentrations of $\mathrm{H}_{3} \mathrm{O}^{+}$and $\mathrm{OH}^{-}$ions, that is, ultimately changes in the $\mathrm{pH}$ value:

$$
\begin{gathered}
\mathrm{NH}_{3}+\mathrm{H}_{2} \mathrm{O} \longleftrightarrow \mathrm{NH}_{4}^{+}+\mathrm{OH}^{-}, \\
\mathrm{NO}_{2}+2 \mathrm{H}_{2} \mathrm{O} \longleftrightarrow \mathrm{NO}_{3}^{-}+\mathrm{H}_{3} \mathrm{O}^{+}+\left(\frac{1}{2}\right) \mathrm{H}_{2}, \\
\mathrm{NO}+3 \mathrm{H}_{2} \mathrm{O} \longleftrightarrow \mathrm{NO}_{3}^{-}+\mathrm{H}_{3} \mathrm{O}^{+}+\left(\frac{3}{2}\right) \mathrm{H}_{2}, \\
\mathrm{~N}_{2} \mathrm{O}+5 \mathrm{H}_{2} \mathrm{O} \longleftrightarrow 2 \mathrm{NH}_{4}^{+}+2 \mathrm{OH}^{-}+2 \mathrm{O}_{2} .
\end{gathered}
$$

Considering these detection reactions, we have seen that these give rise to different levels of gas response. This fact is illustrated in Table 1.

Attempting to relate the magnitude of the measured gas sensitivities to the physico-chemical properties of the
TABLE 1: Comparison of measured gas sensitivities to chemical data of the different analyte gases.

\begin{tabular}{lcccc}
\hline $\begin{array}{l}\text { Analyte } \\
\text { gas }\end{array}$ & $S_{\text {gas }}[c=100 \mathrm{ppm}]$ & Solubility & $p K_{\mathrm{a}}$ & $p K_{\mathrm{b}}$ \\
\hline $\mathrm{NO}_{2}$ & 30 & hydrolyses $(<2550 \mathrm{~g} / \mathrm{L})$ & -1.32 & \\
$\mathrm{NO}$ & 28 & $0.067 \mathrm{~g} / \mathrm{L}$ & -1.32 & \\
$\mathrm{CO}_{2}$ & n.a. & $0.0005 \mathrm{~g} / \mathrm{L}$ & 3.3 & \\
$\mathrm{NH}_{3}$ & 5 & $541 \mathrm{~g} / \mathrm{L}$ & & 4.79 \\
$\mathrm{~N}_{2} \mathrm{O}$ & 0.003 & $1.2 \mathrm{~g} / \mathrm{L}$ & & 4.79 \\
\hline
\end{tabular}

different analyte molecules, we have further proposed that the above reactions are overall results of two partial reactions.

(i) Absorption in the liquid:

$$
\begin{gathered}
\mathrm{NH}_{3}+\mathrm{n} \mathrm{H}_{2} \mathrm{O} \longleftrightarrow\left(\mathrm{NH}_{3}\right)_{\mathrm{n} \text { aq, }} \\
\mathrm{NO}_{2}+\mathrm{H}_{2} \mathrm{O} \longleftrightarrow \mathrm{HNO}_{3}+\left(\frac{1}{2}\right) \mathrm{H}_{2}, \\
\mathrm{NO}+2 \mathrm{H}_{2} \mathrm{O} \longleftrightarrow \mathrm{HNO}_{3}+\left(\frac{3}{2}\right) \mathrm{H}_{2}, \\
\mathrm{~N}_{2} \mathrm{O}+3 \mathrm{H}_{2} \mathrm{O} \longleftrightarrow 2 \mathrm{NH}_{3}+2 \mathrm{O}_{2} .
\end{gathered}
$$

(ii) Electrolytic dissociation inside the liquid:

$$
\begin{gathered}
\mathrm{HNO}_{3}+\mathrm{H}_{2} \mathrm{O} \longleftrightarrow \mathrm{NO}_{3}^{-}+\mathrm{H}_{3} \mathrm{O}^{+} ; \quad \mathrm{pKa}=-1.32, \\
\mathrm{NH}_{3}+\mathrm{H}_{2} \mathrm{O} \longleftrightarrow \mathrm{NH}_{4}^{+}+\mathrm{OH}^{-} ; \quad \text { pKb }=4.79 .
\end{gathered}
$$

The observed ordering of the gas sensitivities then arises from two causes: (i) decreasing ease of absorption due to the necessity of breaking up increasing numbers of $\mathrm{H}_{2} \mathrm{O}$ molecules and of rearranging increasing numbers of covalent bonds to form $\mathrm{HNO}_{3}$ or $\mathrm{NH}_{3}$, and (ii) poorer electrolytic dissociation of $\mathrm{NH}_{3}$ relative to $\mathrm{HNO}_{3}$.

A final comment with regard to gas sensitivities relates to the absence of an observable $\mathrm{CO}_{2}$ gas sensing effect. Within 
our reasoning this latter insensitivity arises from the fact that $\mathrm{CO}_{2}$ does not dissolve readily in water and that the corresponding acid $\mathrm{H}_{2} \mathrm{CO}_{3}$ is only a relatively weak one. It is therefore suggested that the sensor baseline resistance in ambient air is more likely to be determined by the trace levels of $\mathrm{NO}_{2}(<1 \mathrm{ppm})$ than by the much more abundant $\mathrm{CO}_{2}$ ( $400 \mathrm{ppm})$.

6.3. Electrolyte/Semiconductor Interactions. With the absorbed gas concentrations having been converted into $\mathrm{pH}$ changes, the next question is how these changes are communicated to the underlying semiconductor substrate and converted into a conductance change there. To this end, one has to consider energy diagrams like the one shown in Figure 25. This latter diagram shows the relative arrangement of the diamond valence band maximum and the conduction band minimum as arranged on a common scale with the $\mathrm{H}_{2} \mathrm{O} / \mathrm{OH}^{-}$and $\mathrm{H}_{3} \mathrm{O}^{+} / \mathrm{H}_{2} \mathrm{O}$ redox levels in the adsorbed liquid electrolyte. As a common reference energy the vacuum level is drawn as a red dashed line all through this diagram.

Considering this diagram two important points need to be noted. Firstly, gas absorption in the liquid electrolyte leads to $\mathrm{pH}$ changes. $\mathrm{pH}$ changes in turn alter the number of positively charged $\mathrm{H}_{3} \mathrm{O}^{+}$ions at the energy position of the $\mathrm{H}_{3} \mathrm{O}^{+} / \mathrm{H}_{2} \mathrm{O}$ and of $\mathrm{OH}^{-}$ions at the $\mathrm{H}_{2} \mathrm{O} / \mathrm{OH}^{-}$redox couples, respectively. Secondly, provided these redox levels overlapped with filled or empty levels in the diamond valence or conduction bands, neutralisation reactions are enabled by shifting electronic charge across the semiconductor liquid electrolyte interface. Once such a charge transfer has taken place, the changed densities of conduction or valence band electrons give rise to a conductance change, that is, a sensor signal. Referring back to Figure 25, it is seen that there is such a favourable match in the case of the valence band maximum in $\mathrm{H}$-terminated diamond and the $\mathrm{H}_{3} \mathrm{O}^{+} / \mathrm{H}_{2} \mathrm{O}$ redox level. Looking to the right-hand side of Figure 25, one can see that there is a completely unfavourable situation in the case of the liquid electrolyte/oxygenated diamond case. As a consequence, gas sensitivity is seen in the liquid electrolyte/HD system but not in the liquid electrolyte/OD one. The ultimate reason for this difference is the different direction of the $\mathrm{C}-\mathrm{H}$ and $\mathrm{C}-\mathrm{O}$ surface dipoles, leading to large differences in the related electron affinities [58, 64, 65].

Having considered the HD case, the question remains why there is also a dissociative gas sensing effect in the MOX and $\mathrm{a}-\mathrm{Si}: \mathrm{H}$ cases. This latter question is answered by the energy diagrams presented in Figures 26 and 27: in the first case there is a favorable match between the $\mathrm{H}_{3} \mathrm{O}^{+} / \mathrm{H}_{2} \mathrm{O}$ level and the bottom of the $\mathrm{SnO}_{2}$ conduction band; in the second case between the $\mathrm{H}_{2} \mathrm{O} / \mathrm{OH}^{-}$level and the bottom of the a$\mathrm{Si}: \mathrm{H}$ conduction band. A full account of the $\mathrm{pH}$ sensitivity of MOX surfaces is provided in [40].

In concluding this chapter we note that all the above arguments apply to semiconductor/liquid electrolyte interfaces which are operated in a floating-gate manner as illustrated in Figure 12(b). In this configuration equilibration between the semiconductor and the liquid electrolyte needs to proceed via charge transfer processes across the semiconductor/liquid electrolyte interface. Charge exchange processes across such interfaces are in general slow due to kinetic hindrances associated with the conversion of electronic to ionic charge and vice versa. Evidence for such hindrances comes from the observation of catalytic enhancement effects when $\mathrm{H}$-termination sites at the HD/liquid electrolyte interface are replaced by $\mathrm{OH}$-termination ones (Figure 13(a)). Another supporting evidence for such hindrances comes from observations on HD sensors operated as $\mathrm{pH}$ sensors in macroscopic volumes of liquid electrolyte using conventional electrochemical three-electrode configurations $[66,67]$.

\section{Summary and Conclusions}

In accordance with the BET isotherm, we found that, at surface temperatures below about $150^{\circ} \mathrm{C}$, a thin layer of adsorbed humidity is likely to exist and to cover the surface of all studied semiconductor materials. Under these conditions a direct gas sensing interaction with the semiconductor surface cannot occur. In case an electronically favourable condition exists, that is, the redox level in the liquid electrolyte matching with either the conduction minimum or the valance band maximum in the semiconductor material, possible $\mathrm{pH}$ changes in the surface electrolyte can be communicated to the electronic system in the underlying semiconductor, and a conductometric gas response can be obtained.

This form of gas sensitivity is limited to gases, which are able to undergo electrolytic dissociation in water, and it is therefore called "dissociative gas response mechanism". Gases that cannot undergo electrolytic dissociation remain largely undetected.

Heating MOX materials through the water evaporation threshold, a direct interaction of the analyte gas molecules with the surface oxygen ions is enabled. Under these conditions, the dissociative gas response vanishes and gives way to the widely known "combustive gas response mechanism".

Heating hydrogen-terminated diamond (HD) specimens beyond the evaporation temperature of the surface electrolyte layer causes both the p-type conductivity in the diamond and the gas response to vanish. Both effects are related to the fact that HD does not support a bulk but rather a surface conductivity that is induced by a transfer of valence electrons to the adsorbed water layer. Direct gassurface interactions with an H-terminated semiconductor surface, therefore, cannot be studied on HD surfaces. HD can be used as an innovative gas sensor material making use of the phenomenon of dissociative room-temperature gas response. Its gas sensing properties can be improved by using the observed effects of temperature, UV light exposure, ozone "cleaning" by oxidation, and catalytic enhancement via $\mathrm{OH}$ surface groups.

Hydrogenated amorphous silicon (a-Si:H) exhibits both an H-terminated surface and a bulk conductivity that is unrelated to the H-termination itself. Heating a-Si:H through the water evaporation threshold, a novel type of gas response can be observed that is far more selective than the combustive gas response at MOX surfaces. It is called "coordinative gas response mechanism". Under heat-dried 
conditions, a predominant response to nitrogen-bearing gases can be observed at a-Si:H surfaces. It involves both the surface bound $\mathrm{H}$ atoms of the a-Si:H films as well as the lone-pair electrons $\left(\mathrm{NH}_{3}\right)$ or three-centre bonds $\left(\mathrm{NO}_{2}\right)$ of nitrogen-containing analyte gas molecules.

\section{References}

[1] W. Göpel and K. D. Schierbaum, " $\mathrm{SnO}_{2}$ sensors: current status and future trends," Sensors and Actuators B, vol. 26, no. 1-3, pp. 1-12, 1995.

[2] D. E. Williams, "Conduction and gas response of semiconductor gas sensors," in Solid State Gas Sensors, pp. 71-123, Adam Hilger, Bristol, UK, 1987.

[3] K. Ihokura and J. Watson, The Stannic Oxide Gas Sensor: Principles and Applications, CRC Press, Boca Raton, Fla, USA, 1994.

[4] S. R. Morrison, "Chemical sensors," Semiconductor Sensors, John Wiley \& Sons, New York, NY, USA, 1994.

[5] H. V. Shurmer, J. W. Gardner, and H. T. Chan, "The application of discrimination technique to alcohols and tobaccos using tin-oxide sensors," Sensors and Actuators, vol. 18, no. 34, pp. 361-371, 1989.

[6] J. W. Gardner and P. N. Bartlett, "Electronic noses: principles and applications," Measurement Science and Technology, vol. 11, no. 7, p. 1087, 2000.

[7] R. Menzel and J. Goschnick, "Gradient gas sensor microarrays for on-line process control-a new dynamic classification model for fast and reliable air quality assessment," Sensors and Actuators B, vol. 68, no. 1, pp. 115-122, 2000.

[8] S. Ahlers, G. Müller, and Th. Doll, "Factors influencing the gas sensitivity of metal oxide materials," in Encyclopedia of Sensors, C. A. Grimes, E. C. Dickey, and M. V. Pisko, Eds., vol. 3, pp. 413-447, The Pennsylvania State University, University Park, $\mathrm{Pa}, \mathrm{USA}, 2006$.

[9] http://www.umweltsensortechnik.de.

[10] J. Spannhake, A. Helwig, O. Schulz, and G. Müller, "Microfabrication of gas sensors," in Solid State Gas Sensing, E. Comini, G. Faglia, and G. Sberveglieri, Eds., pp. 1-46, Springer Science, Business Media, LLC, Berlin, Germany, 2009.

[11] G. Müller, A. Friedberger, P. Kreisl, S. Ahlers, O. Schulz, and T. Becker, "A MEMS toolkit for metal-oxide-based gas sensing systems," Thin Solid Films, vol. 436, no. 1, pp. 34-45, 2003.

[12] G. Sberveglieri, W. Hellmich, and G. Müller, "Silicon hotplates for metal oxide gas sensor elements," Microsystem Technologies, vol. 3, no. 4, pp. 183-190, 1997.

[13] A. Friedberger, P. Kreisl, E. Rose, et al., "Micromechanical fabrication of robust low-power metal oxide gas sensors," Sensors and Actuators B, vol. 93, no. 1-3, pp. 345-349, 2003.

[14] J. Spannhake, O. Schulz, A. Helwig, A. Krenkow, G. Müller, and T. Doll, "High-temperature MEMS heater platforms: long-term performance of metal and semiconductor heater materials," Sensors, vol. 6, no. 4, pp. 405-419, 2006.

[15] E. Comini, G. Faglia, G. Sberveglieri, Z. Pan, and Z. L. Wang, "Stable and highly sensitive gas sensors based on semiconducting oxide nanobelts," Applied Physics Letters, vol. 81, no. 10, p. 1869, 2002.

[16] E. Comini, "Metal oxide nano-crystals for gas sensing," Analytica Chimica Acta, vol. 568, no. 1-2, pp. 28-40, 2006.

[17] M. Epifani, L. Francioso, P. Siciliano, et al., " $\mathrm{SnO}_{2}$ thin films from metalorganic precursors: synthesis, characterization, microelectronic processing and gas-sensing properties," Sensors and Actuators B, vol. 124, no. 1, pp. 217-226, 2007.
[18] M. Epifani, A. Helwig, J. Arbiol, et al., " $\mathrm{TiO}_{2}$ thin films from titanium butoxide: synthesis, Pt addition, structural stability, microelectronic processing and gas-sensing properties," Sensors and Actuators B, vol. 130, no. 2, pp. 599-608, 2008.

[19] F. Hernandez-Ramirez, J. D. Prades, A. Tarancon, et al., "Portable microsensors based on individual $\mathrm{SnO}_{2}$ nanowires," Nanotechnology, vol. 18, no. 49, Article ID 495501, 5 pages, 2007.

[20] J. D. Prades, R. Jimenez-Diaz, F. Hernandez-Ramirez, et al., "Ultralow power consumption gas sensors based on selfheated individual nanowires," Applied Physics Letters, vol. 93, no. 12, Article ID 123110, 3 pages, 2008.

[21] J. Zhao, L.-H. Huo, S. Gao, H. Zhao, and J.-G. Zhao, "Alcohols and acetone sensing properties of $\mathrm{SnO}_{2}$ thin films deposited by dip coating," Sensors and Actuators B, vol. 115, no. 1, pp. 460-464, 2006.

[22] H. C. Wang, Y. Li, and M. J. Yang, "Fast response thin film $\mathrm{SnO}_{2}$ gas sensors operating at room temperature," Sensors and Actuators B, vol. 119, no. 2, pp. 380-383, 2006.

[23] K. Anothainart, M. Burgmair, A. Karthigeyan, M. Zimmer, and I. Eisele, "Light enhanced $\mathrm{NO}_{2}$ gas sensing with tin oxide at room temperature: conductance and work function measurements," Sensors and Actuators B, vol. 93, no. 1-3, pp. 580-584, 2003.

[24] B.-Y. Wei, M.-C. Hsu, P.-G. Su, H.-M. Lin, R.-J. Wu, and H.-J. Lai, "A novel $\mathrm{SnO}_{2}$ gas sensor doped with carbon nanotubes operating at room temperature," Sensors and Actuators B, vol. 101, no. 1-2, pp. 81-89, 2004.

[25] C. Baratto, E. Comini, G. Faglia, G. Sberveglieri, M. Zha, and A. Zappettini, "Metal oxide nanocrystals for gas sensing," Sensors and Actuators B, vol. 109, no. 1, pp. 2-6, 2005.

[26] M. Suchea, N. Katsarakis, S. Christoulakis, S. Nikolopoulou, and G. Kiriakidis, "Low temperature indium oxide gas sensors," Sensors and Actuators B, vol. 118, no. 1-2, pp. 135141, 2006.

[27] E. Comini, A. Cristalli, G. Faglia, and G. Sberveglieri, "Light enhanced gas sensing properties of indium oxide and tin dioxide sensors," Sensors and Actuators B, vol. 65, no. 1, pp. 260-263, 2000.

[28] E. Comini, G. Faglia, and G. Sberveglieri, "UV light activation of tin oxide thin films for $\mathrm{NO}_{2}$ sensing at low temperatures," Sensors and Actuators B, vol. 78, no. 1-3, pp. 73-77, 2001.

[29] T.-Y. Yang, H.-M. Lin, B.-Y. Wie, C.-Y. Wu, and C.-K. Lin, "UV enhancement of the gas sensing properties of nano- $\mathrm{TiO}_{2}$," Reviews on Advanced Materials Science, vol. 4, no. 1, pp. 4854, 2003.

[30] S. Mishra, C. Ghanshyam, N. Ram, R. P. Bajpai, and R. K. Bedi, "Detection mechanism of metal oxide gas sensor under UV radiation," Sensors and Actuators B, vol. 97, no. 2-3, pp. 387390, 2004.

[31] T. Fu, "Sensing properties and mechanism of gas sensor for $\mathrm{H}_{2} \mathrm{~S}$ and $\mathrm{NO}_{2}$ based on $\left[\mathrm{Cu}_{5}\left(\text { bipyO }{ }_{2}\right)_{6} \mathrm{Cl}_{8}\right] \mathrm{Cl}_{2}$," Sensors and Actuators B, vol. 123, no. 2, pp. 1113-1119, 2007.

[32] A. Helwig, G. Müller, M. Eickhoff, and G. Sberveglieri, "Dissociative gas sensing at metal oxide surfaces," IEEE Sensors Journal, vol. 7, no. 12, pp. 1675-1679, 2007.

[33] A. Helwig, G. Müller, O. Weidemann, A. Härtl, J. A. Garrido, and M. Eickhoff, "Gas sensing interactions at hydrogenated diamond surfaces," IEEE Sensors Journal, vol. 7, no. 9, pp. 1349-1353, 2007.

[34] A. Helwig, G. Müller, J. A. Garrido, and M. Eickhoff, "Gas sensing properties of hydrogen-terminated diamond," Sensors and Actuators B, vol. 133, no. 1, pp. 156-165, 2008. 
[35] A. Helwig, G. Müller, G. Sberveglieri, and G. Faglia, "Gas sensing properties of hydrogenated amorphous silicon films," IEEE Journal of Sensors, vol. 7, no. 11, pp. 1506-1512, 2007.

[36] F. Maier, M. Riedel, B. Mantel, J. Ristein, and L. Ley, "Origin of surface conductivity in diamond," Physical Review Letters, vol. 85, no. 16, pp. 3472-3475, 2000.

[37] J. Ristein, M. Riedel, and L. Ley, "Electrochemical surface transfer doping the mechanism behind the surface conductivity of hydrogen-terminated diamond," Journal of the Electrochemical Society, vol. 151, no. 10, pp. E315-E321, 2004.

[38] S. Ahlers, G. Müller, and T. Doll, "A rate equation approach to the gas sensitivity of thin film metal oxide materials," Sensors and Actuators B, vol. 107, no. 2, pp. 587-599, 2005.

[39] G. Sberveglieri, "Recent developments in semiconducting thin-film gas sensors," Sensors and Actuators B, vol. 23, no. 2-3, pp. 103-109, 1995.

[40] D. E. Yates, S. Levine, and T. W. Healy, "Site-binding model of the electrical double layer at the oxide/water interface," Journal of the Chemical Society, Faraday Transactions 1, vol. 70, pp. 1807-1818, 1974.

[41] S. Brunauer, P. H. Emmett, and E. Teller, "Adsorption of gases in multimolecular layers," Journal of the American Chemical Society, vol. 60, no. 2, pp. 309-319, 1938.

[42] H.-D. Dörfler, Grenzflächen und kolloid-Disperse Systeme: Physik und Chemie, Springer, Berlin, Germany, 2002.

[43] I. Langmuir, "The constitution and fundamental properties of solids and liquids-part I: solids," Journal of the American Chemical Society, vol. 38, no. 11, pp. 2221-2295, 1916.

[44] S. Qi, K. J. Hay, M. J. Rood, and M. P. Cal, "Equilibrium and heat of adsorption for water vapor and activated carbon," Journal of Environmental Engineering, vol. 126, no. 3, pp. 267$271,2000$.

[45] F. Kohlrausch, Praktische Physik 3, Tabellen und Diagramme, W. G. Alberts ed., B. G. Teubner, Stuttgart, Germany, 23 edition, 1986.

[46] M. I. Landstrass and K. V. Ravi, "Hydrogen passivation of electrically active defects in diamond," Applied Physics Letters, vol. 55, no. 14, pp. 1391-1393, 1989.

[47] T. Maki, S. Shikama, M. Komori, Y. Sakaguchi, K. Sakuta, and T. Kobayashi, "Hydrogenating effect of single-crystal diamond surface," Japanese Journal of Applied Physics, vol. 31, no. 10A, pp. 1446-1449, 1992.

[48] A. Hokazono and H. Kawarada, "Enhancement/depletion surface channel field effect transistors of diamond and their logic circuits," Japanese Journal of Applied Physics, vol. 36, no. 12A, pp. 7133-7139, 1997.

[49] K. Hayashi, S. Yamanaka, H. Okushi, and K. Kajimura, "Study of the effect of hydrogen on transport properties in chemical vapor deposited diamond films by Hall measurements," Applied Physics Letters, vol. 68, no. 3, pp. 376-378, 1996.

[50] J. A. Garrido, A. Härtl, S. Kuch, M. Stutzmann, O. A. Williams, and R. B. Jackmann, " $p \mathrm{H}$ sensors based on hydrogenated diamond surfaces," Applied Physics Letters, vol. 86, no. 7, Article ID 073504, 3 pages, 2005.

[51] J. Kanicki, Amorphous and Microcrystalline Semiconductor Devices, Artech House, Boston, Mass, USA, 1992.

[52] J. Pankove, Ed., Semiconductors and Semimetals, vol. 21D, Academic Press, New York, NY, USA, 1984.

[53] W. Luft and Y. S. Tsuo, Hydrogenated Amorphous Silicon Alloy Deposition Processes, Marcel Dekker, New York, NY, USA, 1993.

[54] F. J. Kampas and R. W. Griffith, "Hydrogen elimination during the glow-discharge deposition of a-Si:H alloys," Applied Physics Letters, vol. 39, no. 5, pp. 407-409, 1981.
[55] M. Tanielian, H. Fritzsche, C. C. Tsai, and E. Symbalisty, "Effect of adsorbed gases on the conductance of amorphous films of semiconducting silicon-hydrogen alloys," Applied Physics Letters, vol. 33, no. 4, pp. 353-356, 1978.

[56] M. Tanielian, M. Chatani, H. Fritzsche, V. Smid, and P. D. Persans, "Effect of adsorbates and insulating layers on the conductance of plasma deposited a-Si:H," Journal of NonCrystalline Solids, vol. 35-36, no. 1, pp. 575-580, 1980.

[57] M. Tanielian, "Adsorbate effects on the electrical conductance of a-Si:H," Philosophical Magazine B, vol. 45, no. 4, pp. 435$462,1982$.

[58] J. B. Cui, J. Ristein, and L. Ley, "Dehydrogenation and the surface phase transition on diamond (111): kinetics and electronic structure," Physical Review B, vol. 59, no. 8, pp. 5847-5856, 1999.

[59] A. Helwig, G. Müller, G. Sberveglieri, and G. Faglia, "Gas response times of nano-scale $\mathrm{SnO}_{2}$ gas sensors as determined by the moving gas outlet technique," Sensors and Actuators B, vol. 126, no. 1, pp. 174-180, 2007.

[60] H. Windischmann and P. Mark, "A model for the operation of a thin-film $\mathrm{SnO}_{x}$ conductancemodulation carbon monoxide sensor," Journal of the Electrochemical Society: Solid-State Science and Technology, vol. 126, no. 4, pp. 627-633, 1979.

[61] D. E. Williams, "Semiconducting oxides as gas-sensitive resistors," Sensors and Actuators B, vol. 57, no. 1-3, pp. 1-16, 1999.

[62] N. Barsan and U. Weimar, "Conduction model of metal oxide gas sensors," Journal of Electroceramics, vol. 7, no. 3, pp. 143$167,2001$.

[63] N. Barsan and U. Weimar, "Understanding the fundamental principles of metaloxide based gas sensors; the example of $\mathrm{CO}$ sensing with $\mathrm{SnO}_{2}$ sensors in the presence of humidity," Journal of Physics: Condensed Matter, vol. 15, pp. R813-R839, 2003.

[64] F. Maier, J. Ristein, and L. Ley, "Electron affinity of plasmahydrogenated and chemically oxidized diamond (100) surfaces," Physical Review B, vol. 64, no. 16, Article ID 165411, 7 pages, 2001.

[65] R. S. Gi, T. Mizumasa, Y. Akiba, Y. Hirose, T. Kurosu, and M. Iida, "Formation mechanism of p-type surface conductive layer on deposited diamond films," Japanese Journal of Applied Physics, vol. 34, no. 10, pp. 5550-5555, 1995.

[66] J. A. Garrido, A. Härtl, M. Dankerl, et al., "The surface conductivity at the diamond/aqueous electrolyte interface," Journal of the American Chemical Society, vol. 130, no. 12, pp. 4177-4181, 2008.

[67] M. Dankerl, A. Reitinger, M. Stutzmann, and J. A. Garrido, "Resolving the controversy on the $\mathrm{pH}$ sensitivity of diamond surfaces," Physica Status Solidi. Rapid Research Letetrs, vol. 2, no. 1, pp. 31-33, 2008. 

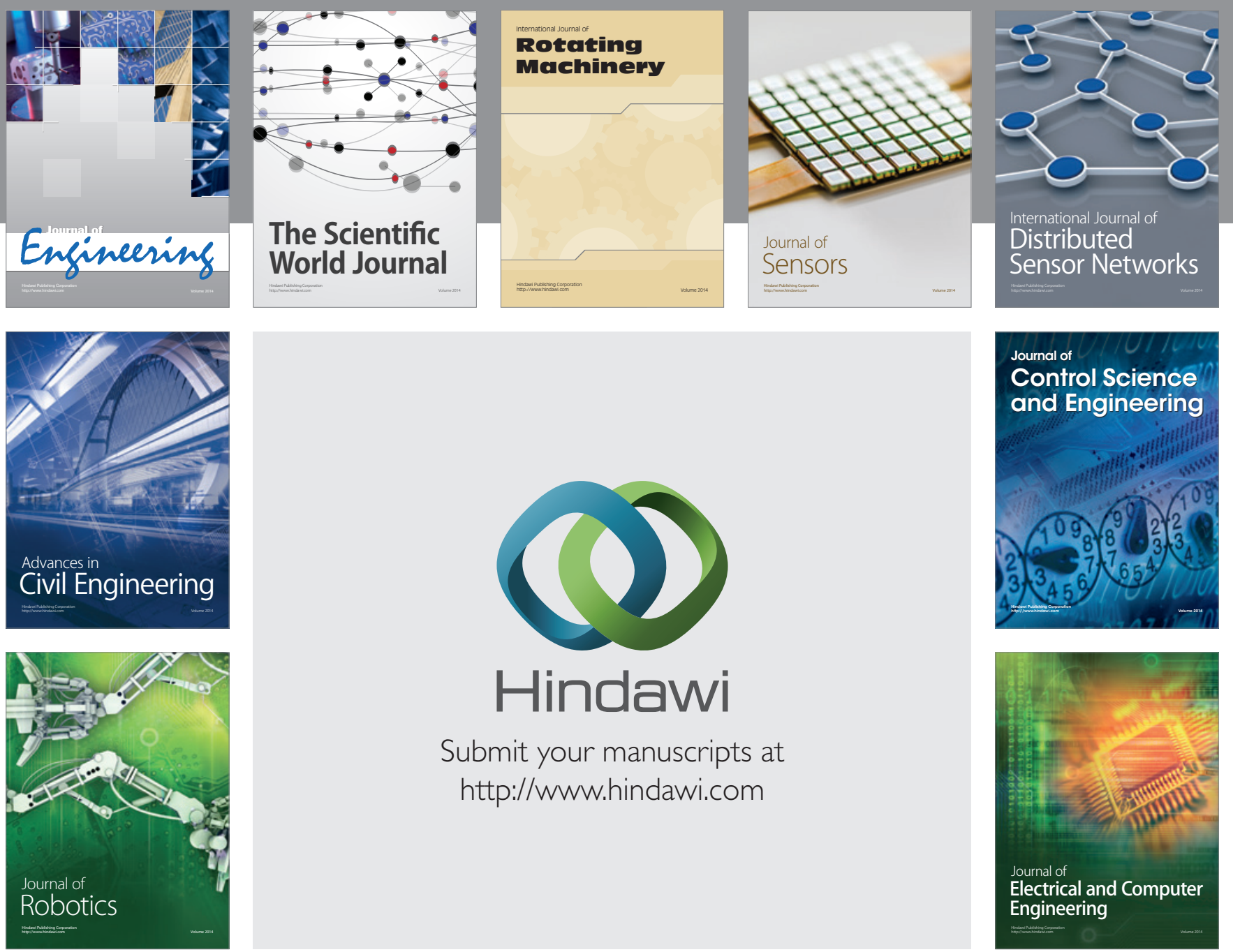

Submit your manuscripts at

http://www.hindawi.com
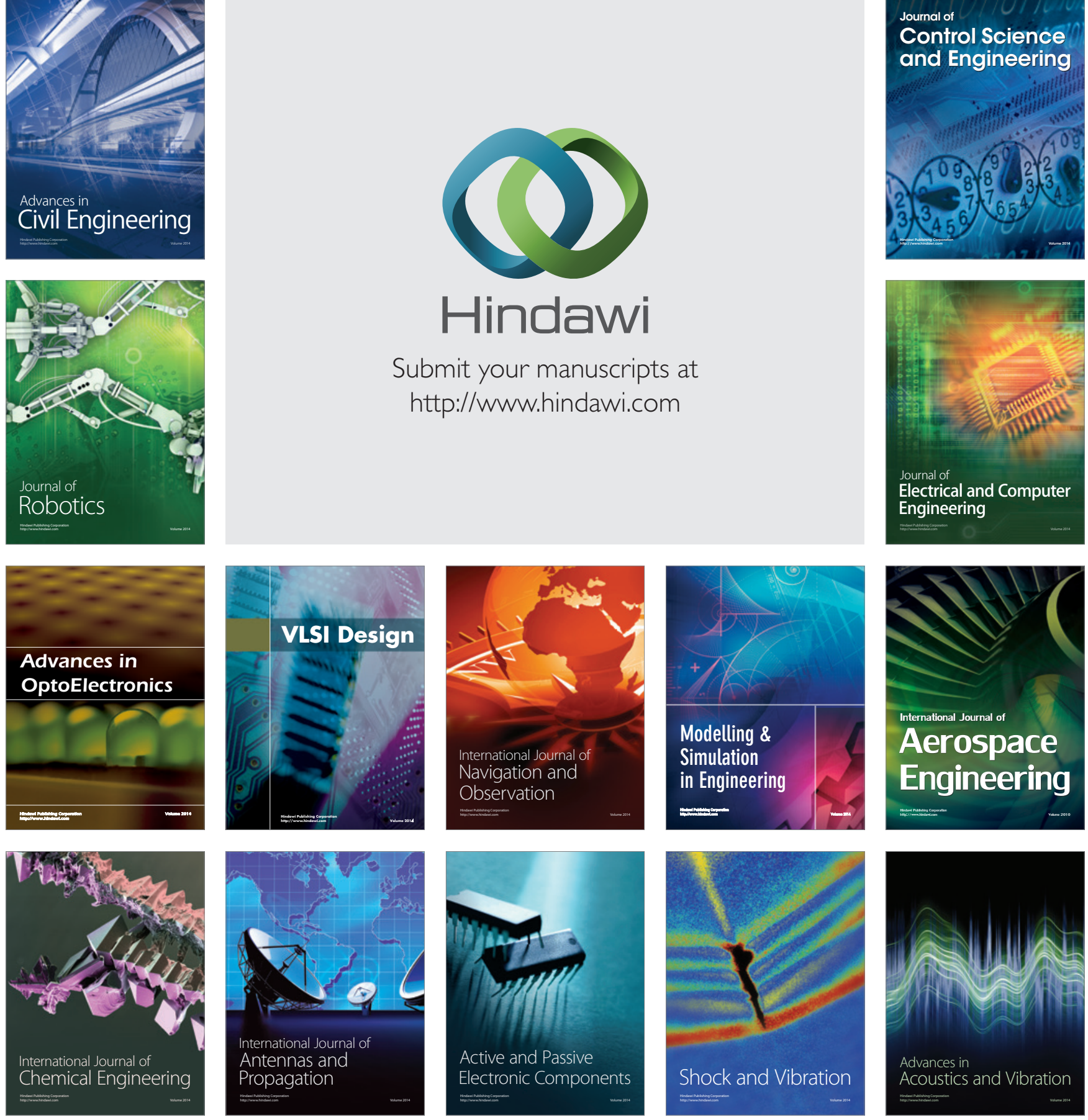